\title{
INSULATED ELECTROCARDIOGRAM ELECTRODES
}

by

ROBERT MYERS DAVID, B.S. in E.E.

\author{
A THESIS \\ IN \\ ELECTRICAL ENGINEERING \\ Submitted to the Graduate Faculty \\ of Texas Tech University in \\ Partial Fulfillment of \\ the Requirement for \\ the Degree of \\ MASTER OF SCIENCE \\ IN \\ ELECTRICAL ENGINEERING \\ APPROVED
}

U ted, 197】 


$$
\begin{aligned}
& A C \\
& 805 \\
& T 3 \\
& 1772 \\
& 100.15 \\
& \text { Cop. } 2
\end{aligned}
$$

\section{ACKNOWLEDGEMENTS}

I would like to thank Dr. W.M. Portnoy for his encouragement during the development of the insulated electrodes and for his assistance in the preparation of this thesis. I also thank Dr. R.H. Seacat and $\mathrm{Dr}$. W.T. Ford for serving on my committee. Mr. J.L. Day was also of help in the electrode development. 


\section{TABLE OF CONTENTS}

ACKNOWLEDGEMENTS .............................

LIST OF TABLES .................... . . . iv

LIST OF FIGURES ...................

I. INTRODUCTION ................... 1

II. THE NATURE OF THE ECG SIGNAL ........... 4

III. THE INSULATED ECG ELECTRODE SYSTEM . . . . . . . . 9

IV. SYSTEM COMPONENT DESIGN . . . . . . . . . 12

A. Selection of Dielectric and Substrate . . . . 12

B. Impedance Transforming Circuit . . . . . . 16

V. EXPERIMENTAL PROCEDURES AND RESULTS . . . . . . 26

A. Radio Frequency Sputtering . . . . . . . . 26

B. Substrate Evaluation .......... 34

C. Impedance Transformer . . . . . . . . 35

D. The Insulated Electrode Assembly . . . . . . . 45

E. Measurement of Electrode Characteristics . . . . 51

VI. CONCLUSIONS ............... 62

LIST OF REFERENCES . . . . . . . . . . . . . . . 63 


\section{LIST OF TABLES}

TABLE 1 MATERIALS CHOSEN FOR DIELECTRIC THIN FILM

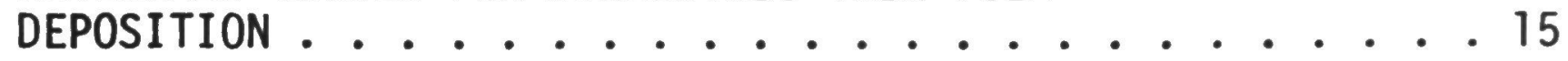

TABLE 2 MEASURED ELECTRODE IMPEDANCE TRANSFORMER PARAMETERS • . . 41

TABLE 3 MEASURED VALUES OF THE LOWER CUTOFF FREQUENCIES FOR THE ELECTRODE SYSTEM AND MEASURED AND CALCULATED VALUES OF SPECIFIC CAPACITANCE FOR THE DIELECTRIC FILMS . . . . 56 


\section{LIST OF FIGURES}

Figure 1 Typical lead II electrocardiogram . . . . . . . 5

Figure 2 Einthoven electrocardiogram triangle ....... . 7

Figure 3 Equivalent circuit for electrocardiogram monitoring system with common mode input ........... 11

Figure $4 \quad$ RC network representing dielectric thin film capacitance and impedance transformer input impedance . . . . . 17

Figure 5 Equivalent circuit for noise coupling into ECG system . . 19 Figure 6 MOSFET impedance transforming circuit . . . . . . 21

Figure 7 Operational amplifier impedance transforming circuit . . 23

Figure 8 R.D. Mathis SP310 r.f. sputtering unit . . . . . 27

Figure 9 Sputtering work chamber with copper screen skirt . . . 29

Figure 10 Final dielectric target configuration ........ 31

Figure 11 Typical interference pattern used for dielectric thin film thickness measurement.......... . 33

Figure 12 Circuit diagram for insulated ECG electrode . . . . . 36

Figure 13 Circuits used to measure impedance transformer input impedance .............. . . 39

Figure 14 Circuit used to measure impedance transformer gain and bandwidth............... . . 42

Figure 15 Side view of insulated ECG electrode . . . . . . . 46

Figure 16 Top view of insulated ECG electrode . . . . . . . . . 47

Figure 17 Photograph of electrode housing before capacitor disc is affixed.............. 49

Figure 18 Photograph of assembled and unassembled electrode . . . 50

Figure 19 Circuit used to obtain frequency response of electrode-subject system ........... 52

Figure 20 Typical system response obtained during system frequency response measurement . . . . . . . . . 54 
Figure 21 Typical lead II electrocardiogram obtained using titanium dioxide films approximately $6000 \mathrm{~A}$ thick and NASA paste electrodes ............ 58

Figure 22 Arrangement of insulated and paste electrodes on subject for lead II monitoring . . . . . . . . . . 60 


\section{CHAPTER I}

\section{INTRODUCTION}

Over the past eighty-three years, beginning with Waller's (1) extensive work on the origin and nature of the human ECG signal, physiologists, chemists, and engineers have been trying to develop the optimum ECG electrode. The electrode must satisfy certain basic requirements: it must be safe, it must provide as distortion free transmittal of data as possible and it must be easy to use.

The electrode which has been found most generally satisfactory for the acquisition of electrocardiographic data is a conducting silversilver chloride electrode which makes a low impedance contact to the skin via a paste electrolyte. ${ }^{\dagger}$ This type of electrode has a good frequency response, low output impedance, and exhibits very little resistive loss. Another very important feature of the electrode is that, for short periods of time, the paste is physiologically inert. However, conductive electrodes, when used for extended periods of time, such as in spacecraft personnel and intensive care patient monitoring, exhibit inadequacies which limit their effectiveness. The paste begins to dry out, resulting in a significant increase in skin-toelectrode resistance and unacceptable biological waveform distortion. Bacterial and fungal growth can take place under electrodes worn for extended periods, (3) and skin irritation occurs when the electrolyte is placed in contact with the skin for long times. ${ }^{(2)}$ Another disadvantage

+An extensive review can be found in Geddes and Baker (Reference 1). 
of the conductive electrode is to be found in its electrical behavior; shifts in d.c. levels at the electrode-skin interface appear as baseline drift in the monitoring system.

An insulated, capacitively coupled electrode offers two primary advantages over the conductive electrode: it can be used without paste on the unprepared skin and it blocks d.c. drift directly at the electrode-skin interface. A number of such insulated electrodes have been fabricated and used with varying success. Dielectric films have been formed on an aluminum base by anodic oxidation, and by depositing quartz, silicon monoxide, and films of organic polymers on aluminum. $(4,5,6,7)$ Thermal oxidation of silicon chips has also been employed. $(8,9)$ Electrodes have been constructed using Mylar as the dielectric material. (10) None of the films which were deposited on aluminum were entirely satisfactory. The quartz, silicon monoxide, and organic films were susceptible to mechanical damage, and the more mechanically sound anodic aluminum oxide films exhibited considerable electrical leakage and were difficult to reproduce. $(11,12)$ The silicon dioxide dielectrics resulted in better thin film properties, reproducibility, and signal quality.

Most of these techniques are limited to the formation of certain types of dielectric films, those which require the participation of the substrate in the $f i 1 \mathrm{~m}$ formation. It was felt that a broader evaluation of insulated ECG electrodes was desirable. Upon completion of the work, electrodes with four different dielectric thin film materials and with the following basic characteristics were fabricated:

a. The electrode assembly could be directly applied to the skin, 
with no paste or skin preparation, simply by using doublesided adhesive tape;

b. the system operated from $a \pm 5$ volt d.c. power supply;

c. the electrode output was directly coupled with zero offset vol tage;

d. electrode reproducibility and signal quality was extremely good.

The following chapters describe the material and procedures used to obtain these electrodes and the electrode behavior. 
CHAPTER II

THE NATURE OF THE ECG SIGNAL

It has been known for some time that the heart, in the process of pumping blood, generates a rhythmic electrical signal which not only regulates the heart function, but can also be detected at points across the surface of the skin. (1) The recording of this signal is called an electrocardiogram. A typical electrocardiogram is shown in Figure 1, along with an enlarged representation of one period of the recording. It should be noted that this is a recording of data taken in the lead II configuration (discussed later), but it indicates the basic structure of the ECG cycle.

Each period of the electrocardiogram (ECG) has been divided into three parts, each of which corresponds to a specific functional part of the heart pumping cycle. The first portion, which is labeled the P-wave in accordance with standard procedure, corresponds to the electrical pulse accompanying the depolarization of the atria, which begins the pumping cycle. The next section is known as the QRS complex and is associated with the depolarization of the ventricles. At very nearly this same time, the atria repolarize, but because of the relative signal magnitudes, the repolarization pulse is usually lost in the QRS complex. The final portion of the period is the T-wave which occurs with the repolarization of the ventricles. Careful analysis of a series of these periods by a trained physician is often a vital tool in the detection of a malfunction of one or more portions of the heart. 

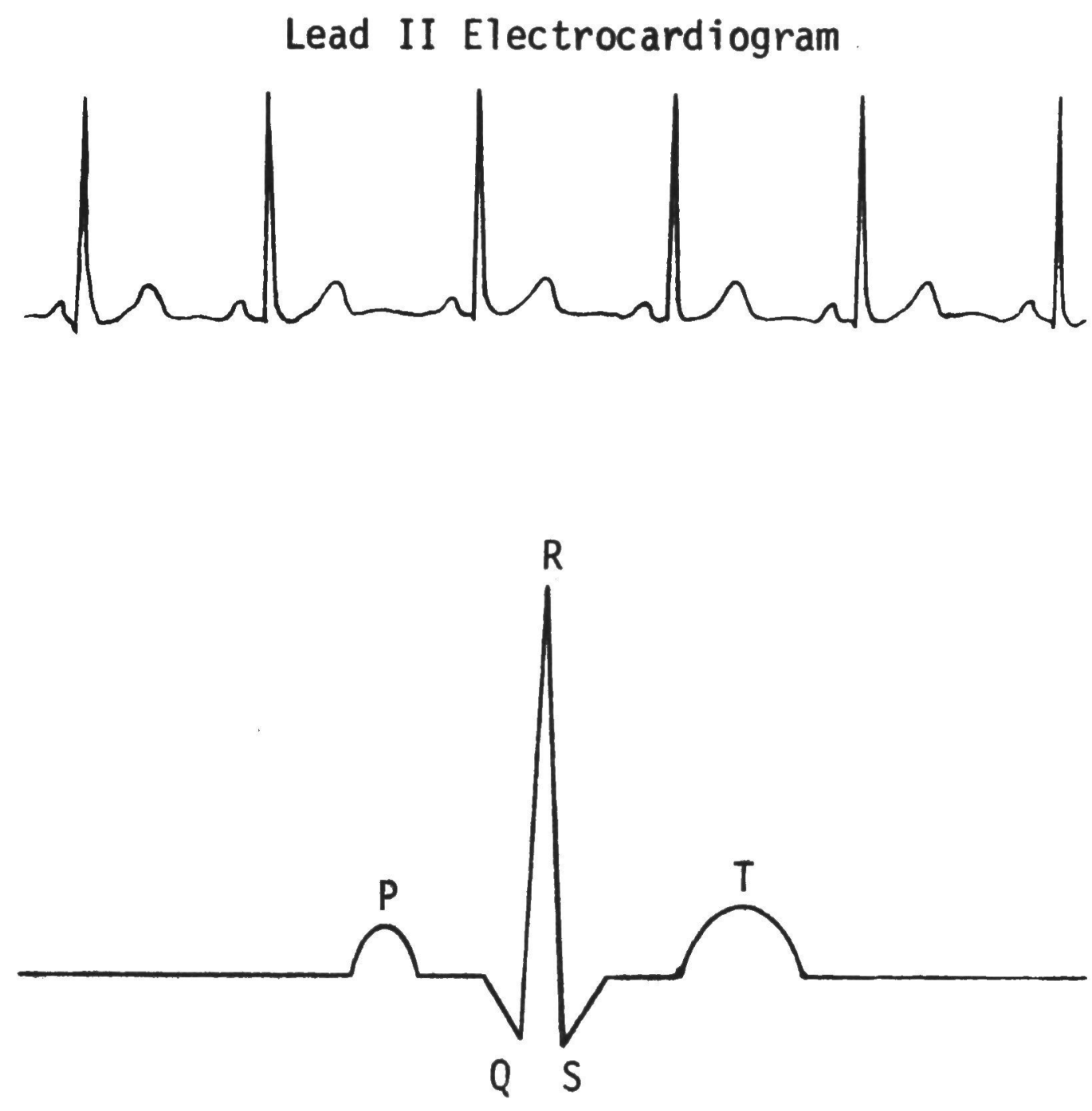

Electrocardiogram Enlargement

Figure 1. Typical lead II electrocardiogram. 
In the early part of this century, a major advancement was made toward the standardization of ECG analysis. Einthoven suggested and demonstrated that a natural triangle (now called the Einthoven triangle) exists about the heart; the triangle has the right arm, left arm, and feet as its vertices. The ECG signals propagating along each of the three sides of the triangle are different in form (though still containing the three basic portions mentioned earlier). (1) The natural configurations which are obtained are labeled in a particular manner. In the lead I position, the negative electrode is on the subject's right arm and the positive electrode on his left arm. The lead II configuration is obtained by moving the positive electrode to his left leg. The third configuration, lead III, is a positive electrode on his left leg and a negative electrode on his left arm. The Einthoven triangle with its three lead configurations is shown in Figure 2. The triangle may obviously be reduced in size, placing the electrodes closer to the heart; most of the measurements which were made in this work were performed in the precordial region. When body grounding is required, the right leg is often chosen and was used in this work.

Additional standards have been developed which specify the characteristics of the electrodes and all peripheral equipment. These standards are the result of intensive study by the Instrumentation Committee on Electrocardiography of the American Heart Association. Realizing that the limiting portion of any ECG system is quite often the direct writing recorder, the Committee suggested that the frequency response of such recorders should not vary in excess of $\pm 0.5 \mathrm{~dB}$ from 


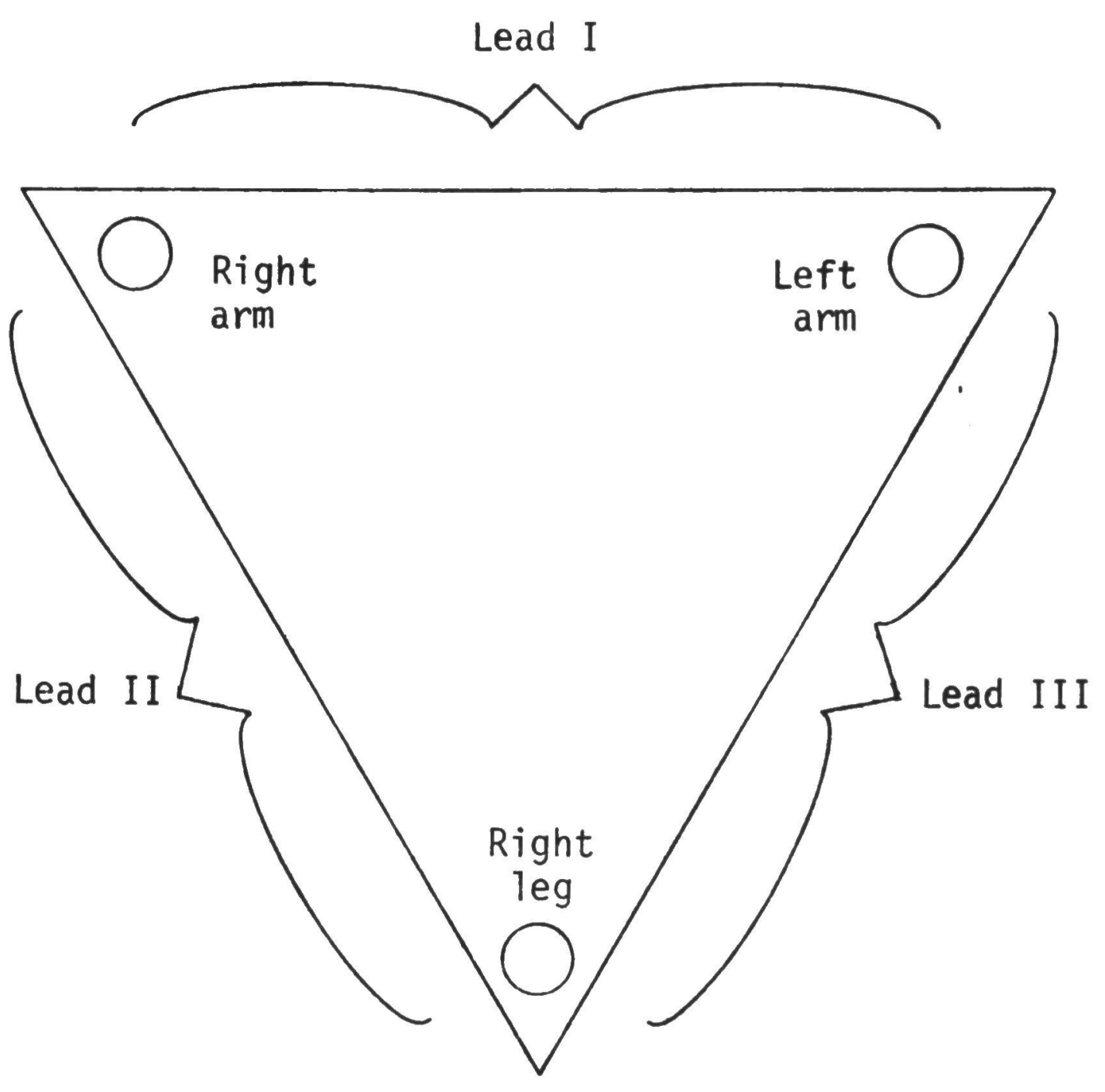

Standard orientation of Einthoven triangle

Figure 2. Einthoven electrocardiogram triangle. 
$0.14 \mathrm{~Hz}$ up to $50 \mathrm{~Hz}$ and that the recorder should have a bandwidth between $0.5 \mathrm{~Hz}$ and $100 \mathrm{~Hz}$. The requirements for preamplifiers external to the recorder are more stringent. Flatness of $\pm 0.5 \mathrm{~dB}$ should be maintained between $0.14 \mathrm{~Hz}$ and $950 \mathrm{~Hz}$, and the $-3 \mathrm{~dB}$ points should be at or below $0.05 \mathrm{~Hz}$ and at or above $2500 \mathrm{~Hz}$. The intrinsic input noise level for such preamplifiers should not exceed $10 \mu \mathrm{v}(\mathrm{rms})$. The common mode rejection ratio for the monitoring system should not be less than $60 \mathrm{~dB}$ in magnitude. The recommendations assume that $\mathrm{dc}$ coupled electrodes are used. Since insulated ECG electrodes are not dc coupled, a lower $-3 \mathrm{~dB}$ point of $0.01 \mathrm{~Hz}$ and an upper cutoff frequency of greater than $5000 \mathrm{~Hz}$ were chosen in this work. While this is not a perfect correspondence to the dc coupled electrode bandwidth, it is a good approximation here. 


\section{CHAPTER III}

\section{THE INSULATED ECG ELECTRODE SYSTEM}

The insulated ECG electrode was described in the INTRODUCTION, but further explanation of its principle of operation and of certain system characteristics is required. The electrode consists of a thin dielectric film on a conducting substrate chip, arranged so that skin contact is made directly to the dielectric thin film layer. The skin acts as one plate of a simple capacitor while the substrate acts as the other. Because of the nature of capacitive coupling and the requirement of the best possible electrode voltage transfer characteristics, an impedance transformer is required as a buffer between the capacitor and the monitoring device.

This system is designed as a replacement for the standard paste type electrode. It should therefore possess as many of the electrical and physical properties of the paste electrode as possible, and it should be usable with any standard monitoring and recording system. Over a short term, the paste electrodes yield good quality ECG signals, but this is an obvious requirement for any ECG electrode. The paste electrode can be made quite small, which not only makes it easier to use, but also approaches the ideal point contact desired for best ECG analysis. Because of the direct coupling of the paste electrode, it provides no dc offset voltage at its output.

Perhaps the most important characteristic of the paste electrode is that two such devices of identical design will have closely matched voltage transfer functions. In order to understand the significance 
of this parameter, consider the system of Figure 3 . This represents the equivalent circuit for an ECG monitoring system with some common mode input signal. For simplicity, it is assumed that the unity gain differential amplifier has an infinite common mode rejection ratio so that no common mode signal appears at the output. Now, suppose that electrode $E_{1}$ has a voltage transfer function $G_{1}=1$, while the second electrode has a voltage transfer function of $G_{2}=0.99$. Under these conditions a one volt common mode input signal could result in a 0.01 volt differential signal at the output. The system would thus, even with a perfect differential amplifier, correspond to a system with the poor common mode rejection ratio of $-40 \mathrm{db}$. It is easy to see that even a very small (1\%) difference in transfer functions of the electrodes can cause a large degradation of the common mode rejection vital to a good ECG monitoring system.

The insulated electrode must therefore have design parameters corresponding to the foregoing discussion. In addition to satisfying the frequency response and other requirements described in the INTRODUCTION, it should provide a minimum dc offset and be reasonably small in size. It should also have a transfer function which is the same for all electrodes. The fabrication of an insulcted ECG system satisfying these requirements is discussed in the following chapters. 


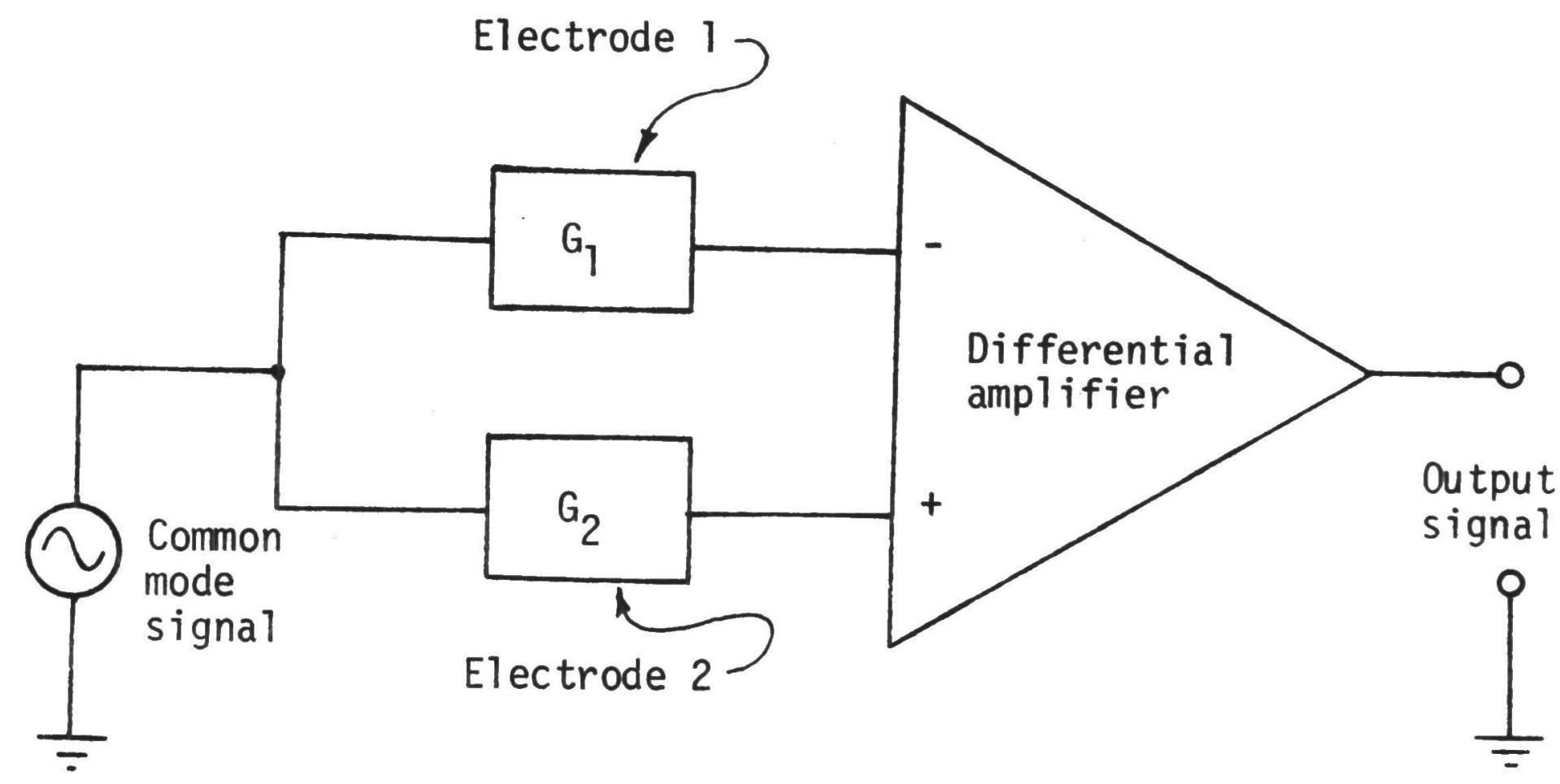

Figure 3. Equivalent circuit for electrocardiogram monitoring system with common mode input. 
CHAPTER IV

SYSTEM COMPONENT DESIGN

\section{A. Selection of Dielectric and Substrate}

It was pointed out in the INTRODUCTION that dielectric-oxide thin films have been formed for use in capacitively coupled ECG electrodes primarily on substrates participating in the oxide growth. Only a limited number of substrates can be used to form such films. In order to permit an evaluation of a variety of dielectrics, several methods of dielectric deposition were examined. A number of procedures have been developed by the semiconductor industry for the controlled and reproducible deposition of dielectric films on various substrates. These procedures fall basically into two categories: chemical depositions and mechanical depositions. The chemical technique contains procedures such as anodic oxidation, thermal oxidation and pyrolytic decomposition, that is, formation from the vapor phase. It should be noted that insulated electrodes described in the INTRODUCTION used a chemical procedure for their formation. The mechanical technique involves procedures such as evaporation in a vacuum or sputtering from a dielectric target.

Anodic oxidation and pyrolytic decomposition are the least successful procedures. Good anodic oxides are very difficult to obtain. Since the anodization takes place in an aqueous electrolyte, ionic species are incorporated into the oxide during its formation; furthermore, anodic oxides are not dense and are susceptible to the formation of pinholes. It is to be expected that dielectrics grown by anodic oxidation are leaky and tend to drift. Also, since the substrate must 
participate in the formation of the oxide, the types of dielectrics available are limited by the number of suitable substrates.

Dielectric thin films which have been deposited by pyrolytic decomposition of chemical vapors can be used to construct capacitively coupled electrodes, but they exhibit defects similar to those exhibited by anodically obtained dielectrics, particularly with respect to their densities and structural integrity. Their density can be increased by subsequent thermal treatment, but at the elevated temperatures required for such work, the substrates are thermally damaged. Furthermore, only a limited number of reactions are available.

The best chemical process appears to be thermal oxidation. Thermally grown oxides are dense and have much better mechanical properties than anodically or pyrolytically formed films. Thermal oxidation, however, has at least one serious drawback; thermal oxide growth requires substrates which can withstand high temperatures.

The mechanical processes offer one common advantage over the chemical processes: film deposition does not require the participation of the substrate. For example, consider the formation of a film of titanium oxide. Chemical formation requires a titanium substrate, whereas an oxide can be mechanically deposited on silicon, aluminum, copper, silver or any suitably prepared material. This choice of substrate material allowed by a mechanical deposition process has obvious advantages.

Evaporation can be performed either by hot filaments or by electron beam bombardment. In filament evaporation, a material is volatilized in a vacuum from a filament or boat heated by passing an 
electric current through it until melting and evaporation of a charge takes place. In electron beam evaporation, the material is bombarded in a vacuum by a high energy electron beam. The high kinetic energy contained in the electron beam is absorbed by the target, resulting in a large increase in target temperature, causing evaporation of the target material. Although these techniques may be employed in the deposition of dielectric thin films, they are used to a much greater advantage when depositing conductive thin films.

The procedure which has been found to be the best for depositing thin films of dielectrics is radio frequency sputtering. A dielectric material is used as a target for bombardment, but instead of a high energy electron beam, ions bombard the surface. These ions are produced in a gas discharge, usually of some inert gas, which has been excited in the presence of $r . f$. energy. As the ions bombard the surface, they dislodge target atoms which deposit on the substrate. A wide variety of dielectric materials can be used for the formation of dielectric thin films.

However, the selection of the dielectric material is not entirely unlimited. Although target cost and dielectric thin film characteristics are important in the choice of material, a major consideration is the compatibility of the dielectric material with the skin. The dielectric must not exhibit any toxicity toward the skin. The toxicity of a wide range of dielectric materials was investigated $(14)$ and five dielectrics were chosen which not only provided a wide range in relative dielectric constants, but which were also inert with respect to human tissue. The materials chosen are shown with their respective dielectric constants in Table 1. 
TABLE 1

MATERIAL CHOSEN FOR DIELECTRIC THIN

FILM DEPOSITION

\begin{tabular}{|l|c|}
\hline Material & $\begin{array}{c}\text { Nominal Relative } \\
\text { Dielectric Constant }\end{array}$ \\
\hline $\mathrm{BaTiO}_{3}$ & 1500 \\
$\mathrm{TiO}_{2}$ & 100 \\
$\mathrm{Ta}_{2} \mathrm{O}_{5}$ & 25 \\
$\mathrm{Al}_{2} \mathrm{O}_{3}$ & 12 \\
$\mathrm{SiO}_{2}$ & 4 \\
\hline
\end{tabular}


Certain constraints exist on the substrate also. The substrate material must be such that it can be polished to a very fine finish and high degree of flatness before receiving the thin film dielectric layer. A non-uniform surface is not likely to provide good quality depositions. The material must also have sufficient strength so that it can be handled without damage occurring to the dielectric (cracking or breaking). It must also have good electrical conductivity to prevent resistive losses.

\section{B. Impedance Transforming Circuit}

The basis of the insulated ECG electrode is the impedance transforming circuit. There are several important characteristics which this circuit must possess, the most important being a very high input impedance. To understand the reason for such a constraint, consider the circuit of Figure 4 . The capacitor $C$ represents the capacitance of the dielectric thin film and $R$ represents the input impedance of the impedance transformer. In the frequency domain, the transfer function of this circuit is given by equation (1),

$$
G(j \omega)=\frac{j \omega}{j \omega+\omega_{0}}
$$

where

$$
\omega_{0}=1 / R C .
$$

Recalling from the previous discussion that a desirable low end $-3 \mathrm{~dB}$ point might be at $0.05 \mathrm{~Hz}$, the requirements on $\mathrm{R}$ and $\mathrm{C}$ can be determined by the following calculation. Since

$$
f_{0}=0.05 \mathrm{~Hz}=\omega_{0} / 2 \pi \text {, }
$$




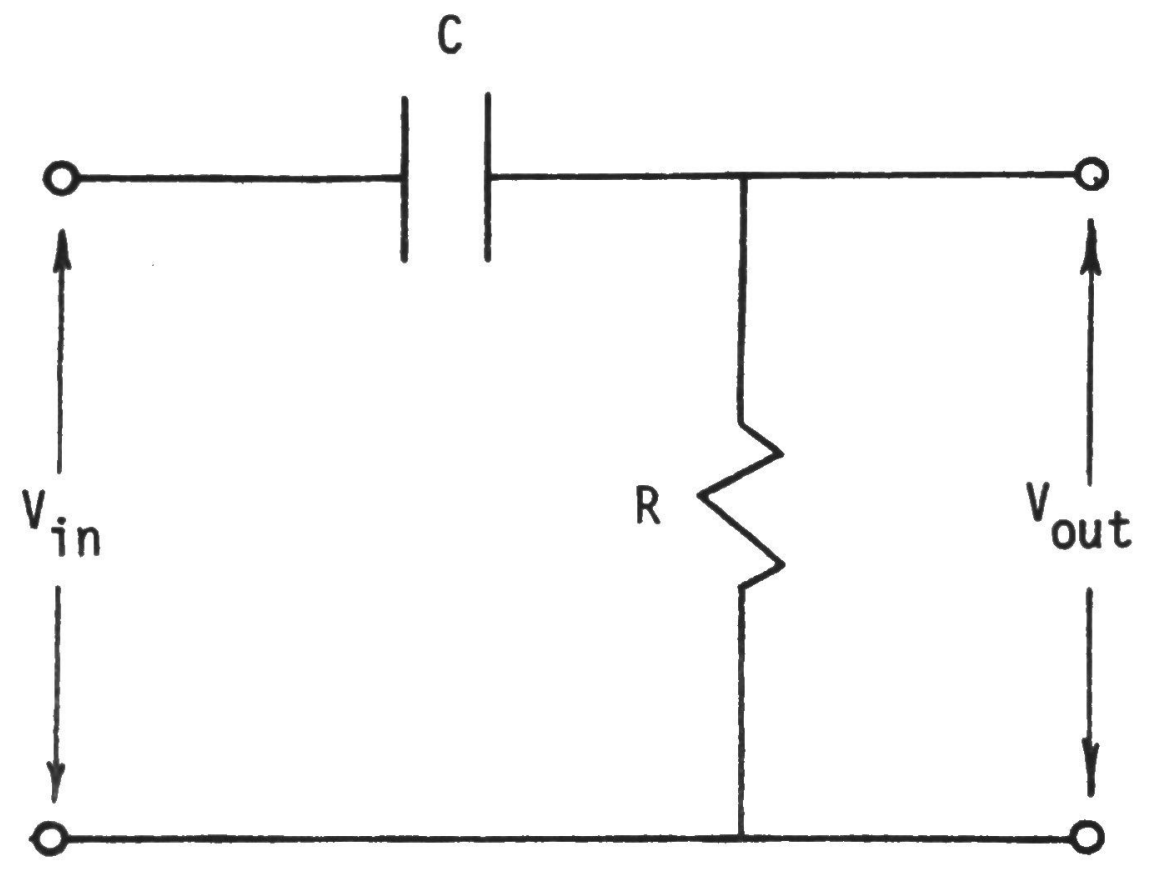

Figure 4. RC network representing dielectric thin film capacitance and impedance transformer input impedance. 


$$
R C=1 / 2 \pi f_{0}=3.18 \text { seconds. }
$$

Considering the areas and estimated thicknesses of the dielectric thin films, it is reasonable to expect a value of $C$ in the neighborhood of $1 \times 10^{-8}$ farads. Equation (2) then implies that $R$ must be at least 318 megohms, which is difficult to obtain. Conventional ECG monitoring devices often have input impedances of only a few hundred kilohms, so that the necessity of the impedance transformer becomes obvious.

The transformer circuit must also be reproducible, that is, when combined with the capacitor, any two electrodes must exhibit identical or as close to identical as possible transfer functions. At midband frequencies, this condition will be determined by the transfer function of the impedance transformer.

Finally, the output impedance of the transformer must be low. The output impedance has an effect on both the noise susceptibility and the voltage transfer qualities of the electrode. Suppose that the output impedance of the electrode is $R_{1}$ and the input impedance of the monitoring unit is $R_{2}$. The voltage transferred to the monitoring unit will be given by equation (3),

$$
v_{\text {in }}=\frac{V_{\text {electrode }} \cdot R_{2}}{R_{1}+R_{2}} \text {. }
$$

It is obvious that if $R_{1}$ is anywhere near the value of $R_{2}$, an appreciable loss of the already low input signal can result. Notice also that if $\mathrm{R}_{1}$ differs between electrodes, different outputs can occur for common mode inputs.

Another reason for making $R_{1}$ very low is that of noise. Figure 5 represents an equivalent circuit whereby extraneous outside electro- 


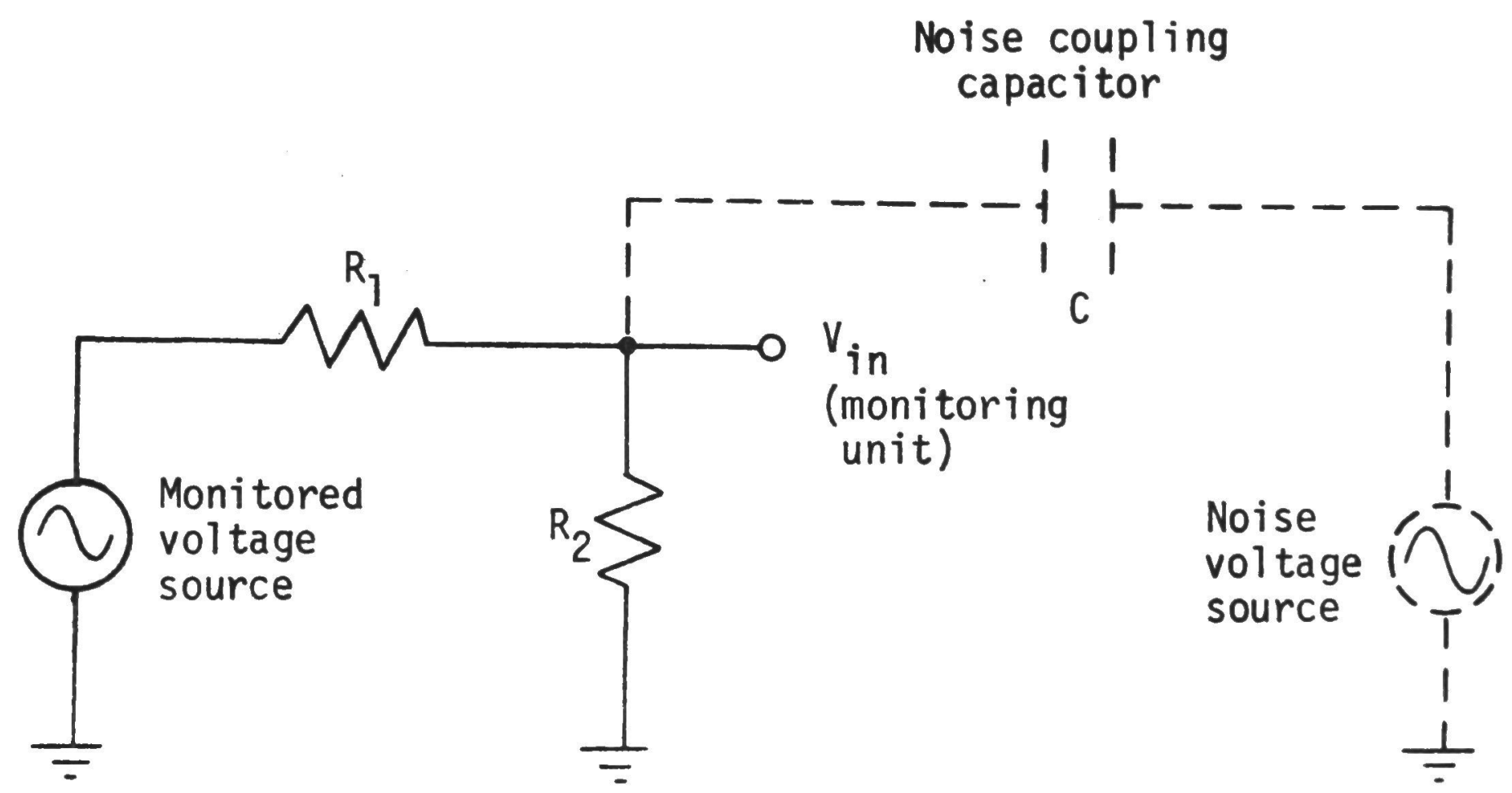

Figure 5. Equivalent circuit for noise coupling into ECG system. 
magnetic noise (e.g., noise from 60 cycle power lines, etc.) can be coupled into the system. C represents the capacitance between the electrode and the noise source. The output will be a summation of desired information and noise. The amount of noise coupled into the system is a function of the impedance transformer output impedance. Equation (1) can be used to represent this transfer, where $R$ is the parallel combination of the two resistors $R_{1}$ and $R_{2}$ mentioned above:

$$
\begin{aligned}
\left|G_{\text {noise }}(j)\right| & =\left|\frac{j \omega}{j \omega+\omega_{0}}\right| \\
& =\frac{\left(\omega^{4}+\omega^{2} \omega_{0}{ }^{2}\right)^{1 / 2}}{\omega_{0}{ }^{2}+\omega^{2}},
\end{aligned}
$$

where

$$
\omega_{0}=1 / R C \text {. }
$$

Taking the modulus of this expression, the absolute value of the transfer function is given by equation (4). It can thus be seen that in order to reduce the noise transfer, $\omega_{0}$ must be increased, implying that $R$ must be as small as possible.

A succession of possible networks for the impedance transformer was considered before arriving at the final choice. The first such circuit is shown in Figure 6 . This simple MOS transistor amplifier possesses two desirable characteristics. It can be designed to have a very large input impedance and the circuit can also be designed so that it requires very little power from its power supply, which is very important for battery operated systems.

Further examination, however, revealed several characteristics which do not lend themselves well to this application. The first problem 


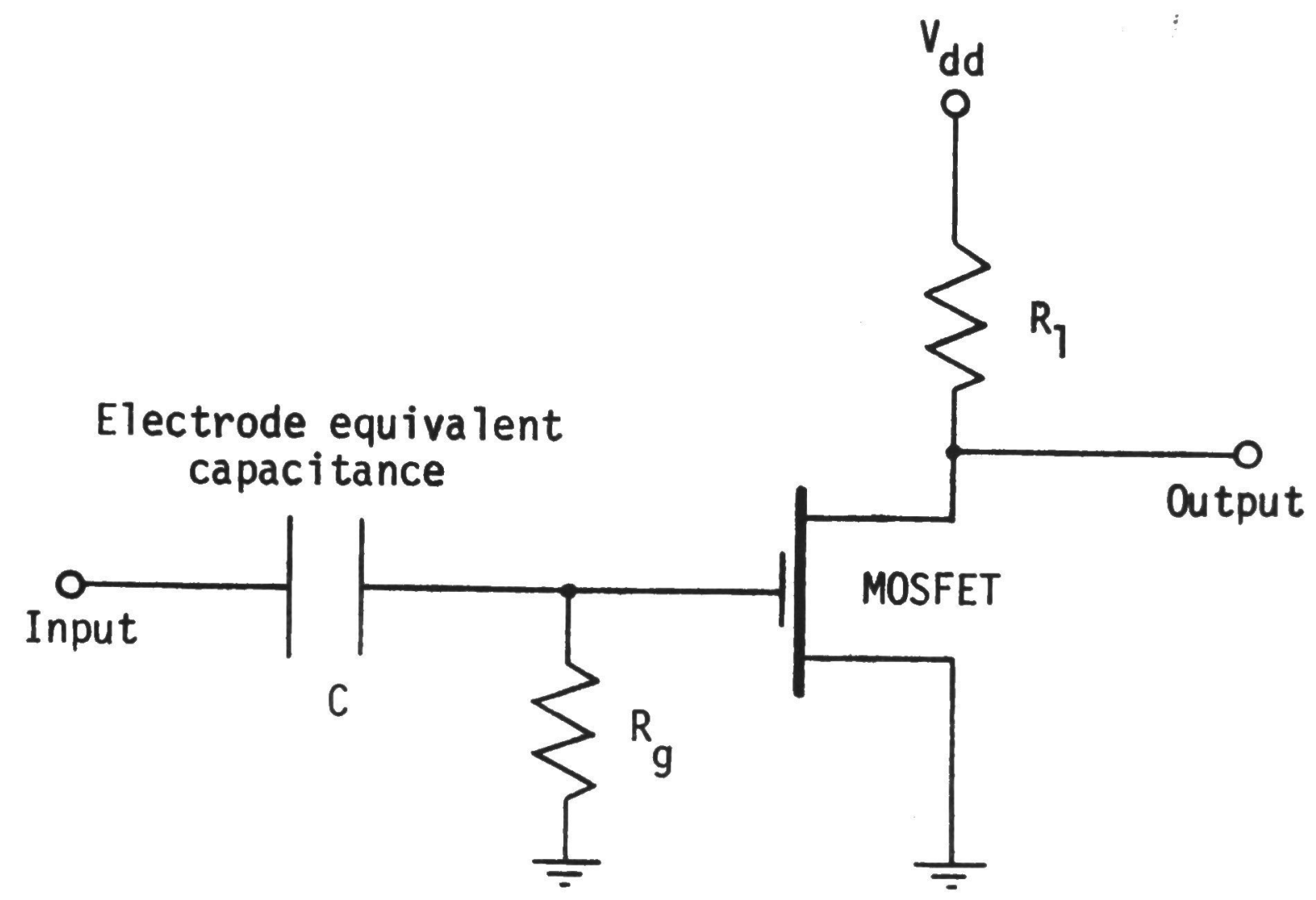

Figure 6. MOSFET impedance transforming circuit. 
arises from the voltage transfer equation. From the $y$ parameters of the MOS device, it can be seen that the voltage transfer function of interest is approximated by equation (5).

$$
G=y_{f} R_{1}
$$

$G$ is the transfer function, $y_{f}$ is the forward transconductance of the device, and $R_{1}$ is the load resistance. The transfer characteristics of this network are not only dependent upon the forward transconductance of the MOS transistor, but also upon $R_{1}$, neither of which are likely to be specified with much better accuracy than $1 \%$. As seen before, a $1 \%$ difference can significantly affect the common mode rejection.

Two other features of this circuit eliminated it from further consideration. The output impedance of this circuit would be several kilohms which is sufficiently large to be undesirable. The other problem arises from the dc offset at the output. Several volts could develop, which would be totally unacceptable for use with some direct coupled recorders.

The next circuit examined for use was the non-inverting operational amplifier configuration of Figure 7 . This circuit offers several improvements over the previous one. The voltage gain in this configuration at midband is given by equation (6),

$$
G_{v}=1+R_{f} / R_{r},
$$

assuming that the open loop gain of the operational amplifier is very large and that the intrinsic input impedance of the operational amplifier is also very large. These assumptions are realistic. The 


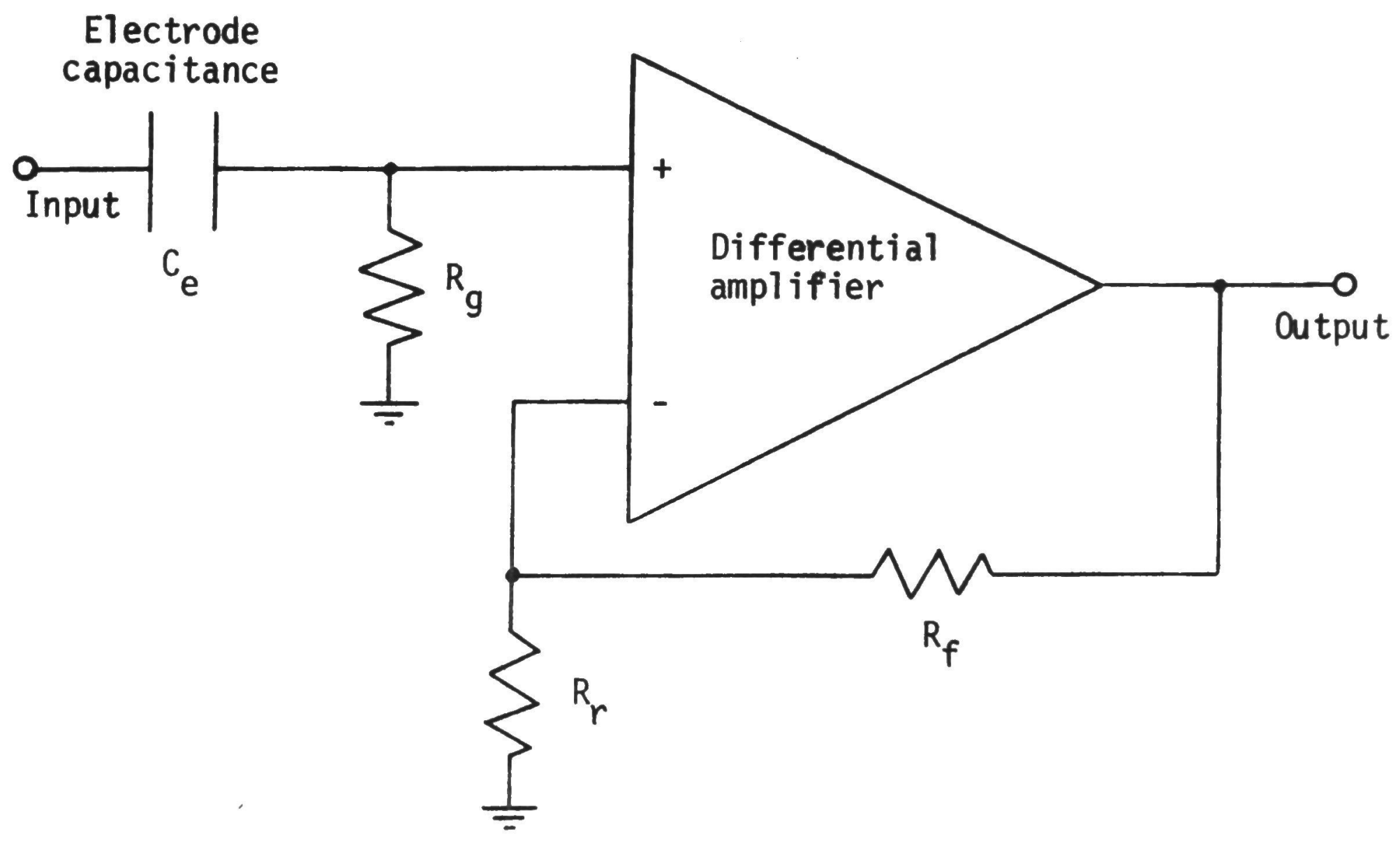

Figure 7. Operational amplifier impedance transforming circuit. 
resulting gain equation is not dependent upon the actual value of the gain of the operational amplifier but only upon the ratio $R_{f} / R_{r}$. This eliminates one of the two possible sources of gain variations which adversely affects the MOS impedance transformer.

Another improvement is in the output impedance of this configuration. Again, under the previous assumptions, the output impedance takes the form of equation (7):

$$
R_{\text {out }}=\frac{\left(R_{\text {io }}\left(1+R_{f} / R_{r}\right)\right)}{A_{0}(\omega)}
$$

where

$$
\begin{aligned}
R_{\text {io }}= & \text { intrinsic output impedance of the operational } \\
& \text { amplifier }
\end{aligned}
$$

and

$$
A_{0}(\omega)=\text { open loop gain of operational amplifier. }
$$

In order to determine the relative magnitude of the output impedance which might be expected, consider a typical operational amplifier. The intrinsic output impedance is seldom greater than 100 ohms, while $A_{0}(\omega)$ is seldom less than 1000. If the quantity $\left(1+R_{f} / R r\right)$ is 10 , as it would be if the gain of the transformer were chosen to be 10 , then the output impedance is only one ohm. This is at least three orders of magnitude less than that of the MOS circuit and is a conservative estimate.

In addition to these features, the dc offset of this configuration can easily be nulled to zero. As well as being an improvement over the MOS circuit, it retains the one major good quality of that circuit. 
The input impedance of this configuration is given by equation (8).

$$
R_{i n}=\frac{R_{g} A_{0}(\omega) R_{i j}}{R_{g}\left(1+R_{f} / R_{r}\right)+A_{0}(\omega) R_{i j}}
$$

where

$$
R_{i j}=\text { intrinsic input impedance of the operational amplifier. }
$$

It can readily be seen that for the condition in which the quantity $\left(A_{0}(\omega) R_{i j}\right)$ is much greater than the quantity $R_{g}\left(1+R_{f} / R_{r}\right)$, which is quite often the case, the input impedance merely becomes $R_{g}$. This is essentially the same as would be expected with the MOS circuit.

The best transformer would have zero output impedance and a voltage transfer function which is not dependent upon circuit parameters. By examining equations (6) and (7), the method whereby this may be closely approximated is readily apparent. If $R_{f}$ is set equal to zero, then $G_{v}$ becomes unity and the output impedance is minimized. For obvious reasons this circuit is called the unity gain configuration and is the circuit chosen for the work described herein. 


\section{CHAPTER V}

\section{EXPERIMENTAL PROCEDURES AND RESULTS}

\section{A. Radio Frequency Sputtering}

The R.D. Mathis SP310 sputtering system of Figure 8 was used for the thin film depositions. The complete system consists of three subsystems: the r.f. generator, the impedance matching unit and the work chamber. The r.f. generator serves two basic purposes. The radio frequency power which it provides creates the dense gas glow discharge between the target electrode and the work chamber containing the substrate which is to receive the sputtered layer. It also causes a bias potential to build up on the surface of the target, aiding in the ion bombardment process. This self-biasing is a direct result of the induced gas glow discharge. The mobilities of the ions and electrons in this plasma are quite different. Since the electrons are much freer, they migrate to the target causing the negative self-biasing effect.

The impedance matching unit is used to couple the $r$.f. energy effectively into the work chamber. The r.f. generator is designed to work into a $50 \mathrm{ohm}$ load, but the work chamber in which the sputtering takes place has a much higher impedance. This matching unit merely performs the necessary impedance transforming function.

The work chamber is designed to fit over an existing 4 or 6 inch vacuum system port. It consists of a water cooled copper target electrode with its back shield, an adjustable water cooled copper substrate, and an accessory base ring. The accessory ring provides feedthroughs for water connections, gas injection, and electrical monitoring devices. 


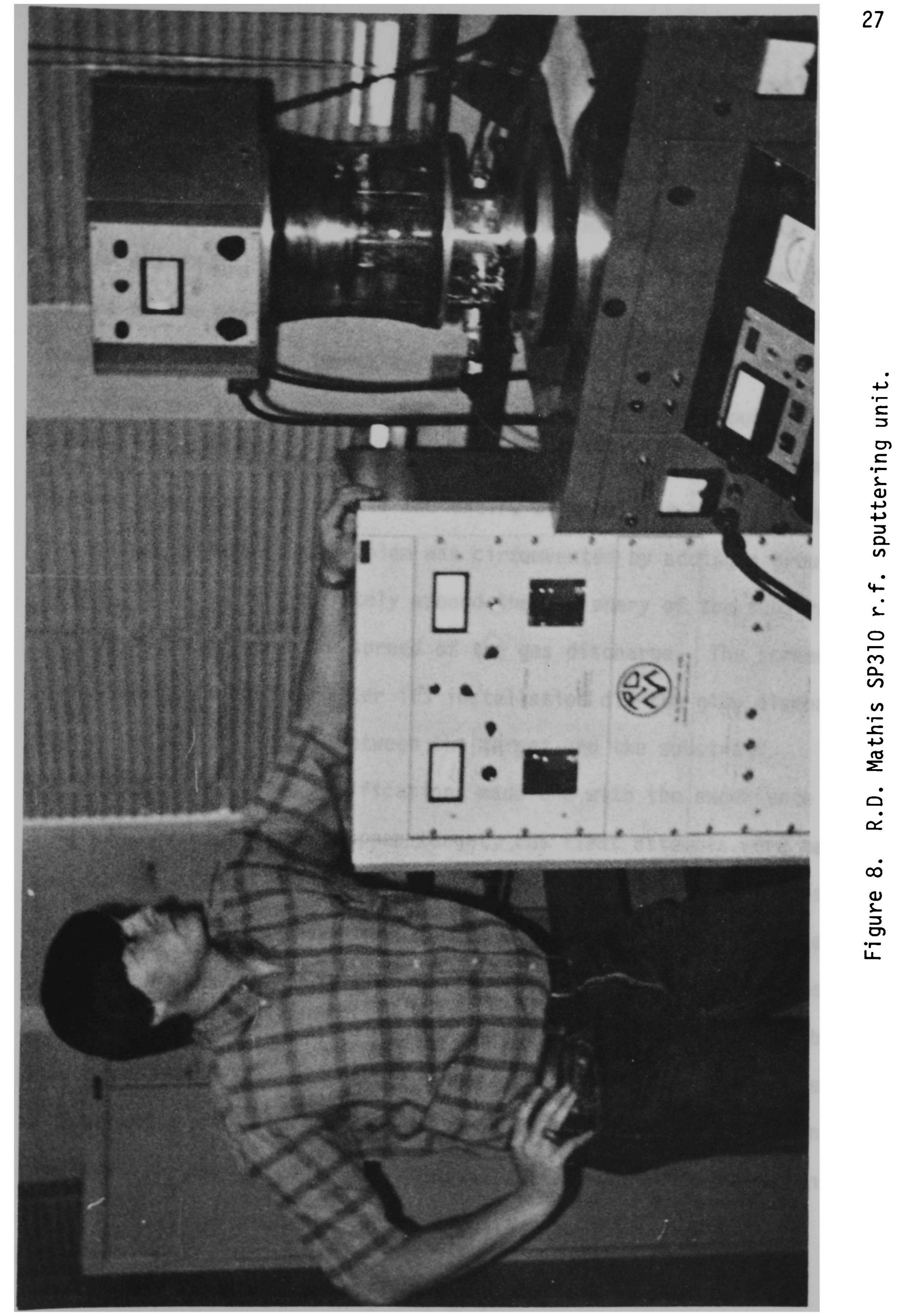


Although the system as a whole was found to be operational when work was commenced, certain modifications were necessary and some time was required to familiarize the operator with the system characteristics. When the first sputtering was attempted, a good impedance match could not be obtained. After considerable examination of the system, the source of the problem was determined and corrected by winding a new coupling coil for the impedance matching unit.

When the system output power was increased beyond about $60 \%$ of maximum, a troublesome phenomenon arose. The glow discharge expanded in such a manner as to engulf the entire work chamber and seep into the vacuum system. The problem was circumvented by adding a grounded copper screen skirt completely around the periphery of the substrate (Figure 9) to prevent the spread of the gas discharge. The screen worked well; at no time after its installation did the glow discharge expand out of the region between the target and the substrate.

With these system modifications made and with the experience gained from sputtering from the copper target, the first attempts were made to sputter the dielectrics. The dielectric targets were $43 / 4$ inches in diameter by $1 / 4$ inch thick discs which were originally to have been connected to the copper target via three metal clips extending from the matching unit base plate. This technique was, however, found to be unacceptable for a variety of reasons. The dielectric targets used were somewhat fragile, so that the clips could not exert sufficient pressure for good electrical or thermal contact to be made between the dielectric target and the copper target. 


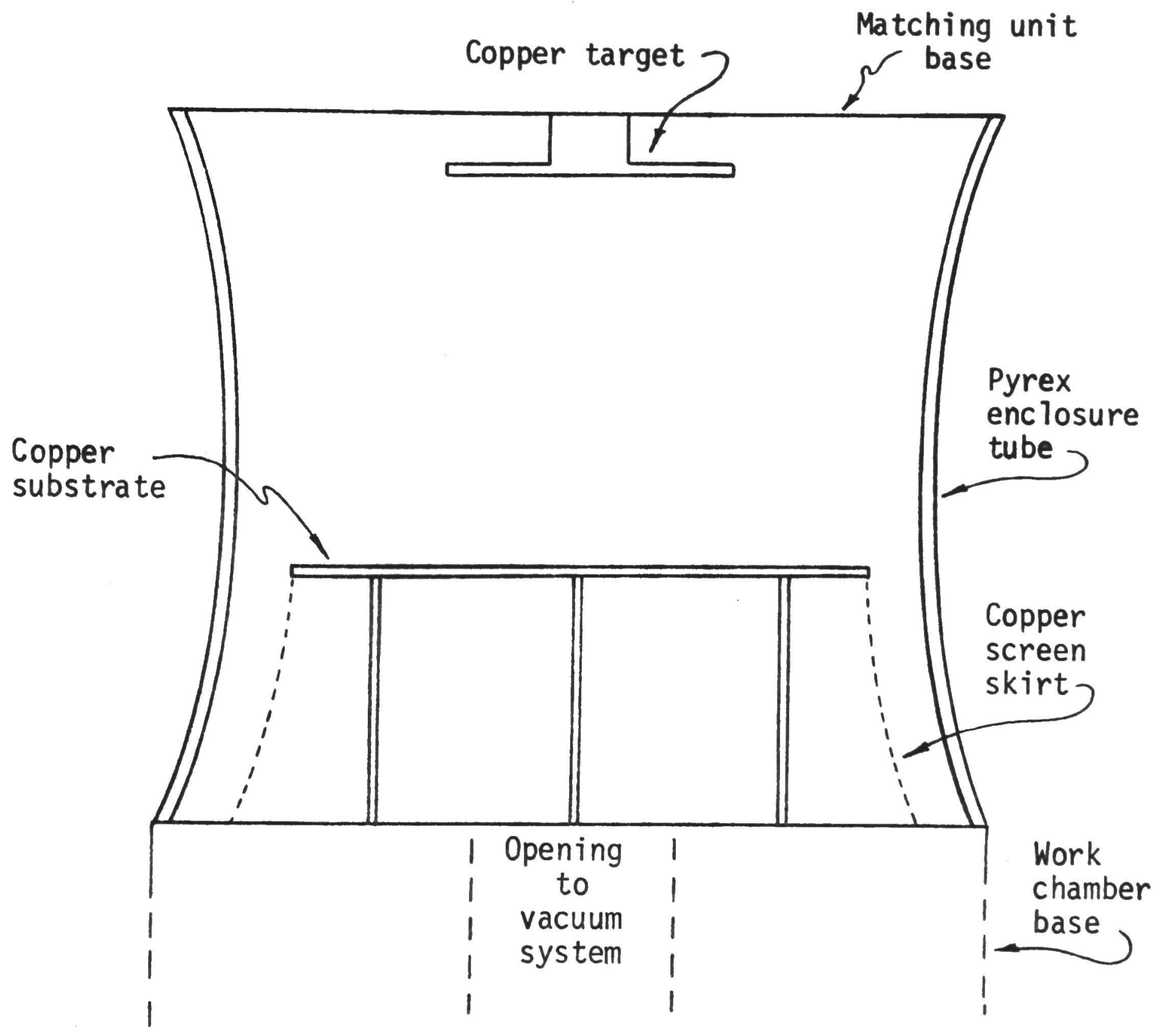

Figure 9. Sputtering work chamber with copper screen skirt. 
The following modifications were made in the system to improve the target to cathode contact. At first, a 3 inch diameter by $1 / 4$ inch thick disc of aluminum with a centrally located bolt was attached to the back of the dielectric target using Eccobond 56C conductive epoxy adhesive. A hole was drilled and tapped into the copper target so that the dielectric target with the attached aluminum disc could be screwed directly into the copper target for improved electrical and thermal contact. The method was found to be unsuitable for several reasons. Good electrical contact was made with the portion of the target which was in contact with the aluminum disc, while the remaining portion of the target had no direct contact. The effective sputtering surface was then less than $50 \%$ of the total surface available, reducing the sputtering efficiency and the effective area of uniform sputtering. Since the electrical contact area was small, so was the thermal contact area, leading to non-uniform heating of the target. This caused one $\mathrm{Al}_{2} \mathrm{O}_{3}$ target to fracture into several pieces during sputtering.

The final configuration is shown in Figure 10. A $45 / 8$ inch diameter by $1 / 8$ inch thick disc of aluminum was secured using three bolts and Eccobond $56 \mathrm{C}$ conductive epoxy adhesive to the 3 inch diameter disc. The entire assembly was then joined to the desired target with Eccobond 59C moldable conductive epoxy adhesive to form one unit easily screwed into the original copper cathode of the sputtering system. This configuration greatly improved electrical and thermal contact. A much larger region of reasonably uniform sputtering was obtained, although, as discussed later, the uniformity of sputtered films was 


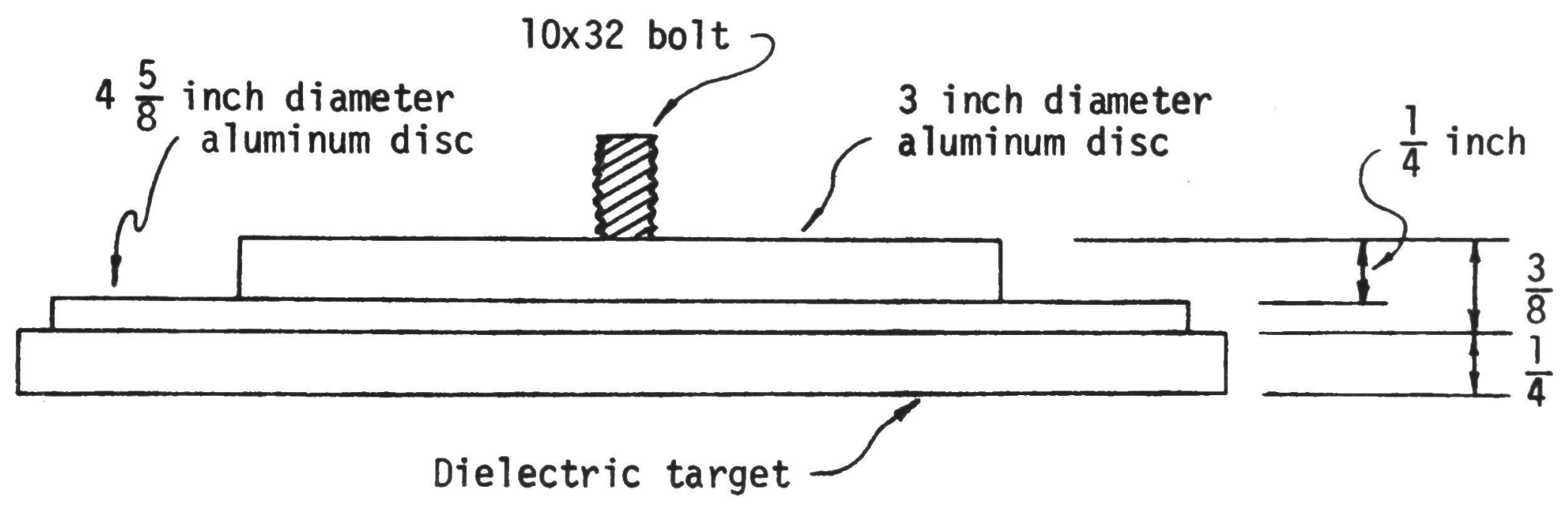

Figure 10. Final dielectric target configuration. 
less than optimum. Not all the results of this system modification were good. By increasing the effective sputtering area, sputtering rates were reduced for a given input power level, not only increasing sputtering times, but also increasing the probability of obtaining pinholes in the thin film.

The thin film thickness was measured with a Hacker Instruments, Inc. Model H/I 700 interference microscope, which was equipped with a Polaroid camera. Before a sputtering run, several pilot slices of silicon were evenly distributed across the work chamber substrate. Each pilot slice was partially covered with a silicon chip, so that deposition took place only on part of the slice, the covered portion remaining clean. Upon completion of the run, the pilot slice was placed under the microscope. After proper adjustment, an interference pattern of the form shown in Figure 11 (a photograph of a typical pattern) was obtained. A shift in interference lines can be noted at the junction between the coated and uncoated surfaces, which corresponds to the difference in thickness. The monochromatic light used to illuminate the pilot slices in all the measurements had a wavelength of $5896 \AA$. The film thickness was found by counting the number of lines shifted across the sputtered step and multiplying by the wavelength of the light.

In the course of evaluating the capacitance of the thin film dielectrics some discrepancies between the measured and computed values were noted (see Table 3 and the associated discussion). Since the calculated value depended upon the thickness of the dielectric sputtered on a pilot slice, it was conjectured that the actual thickness might be 


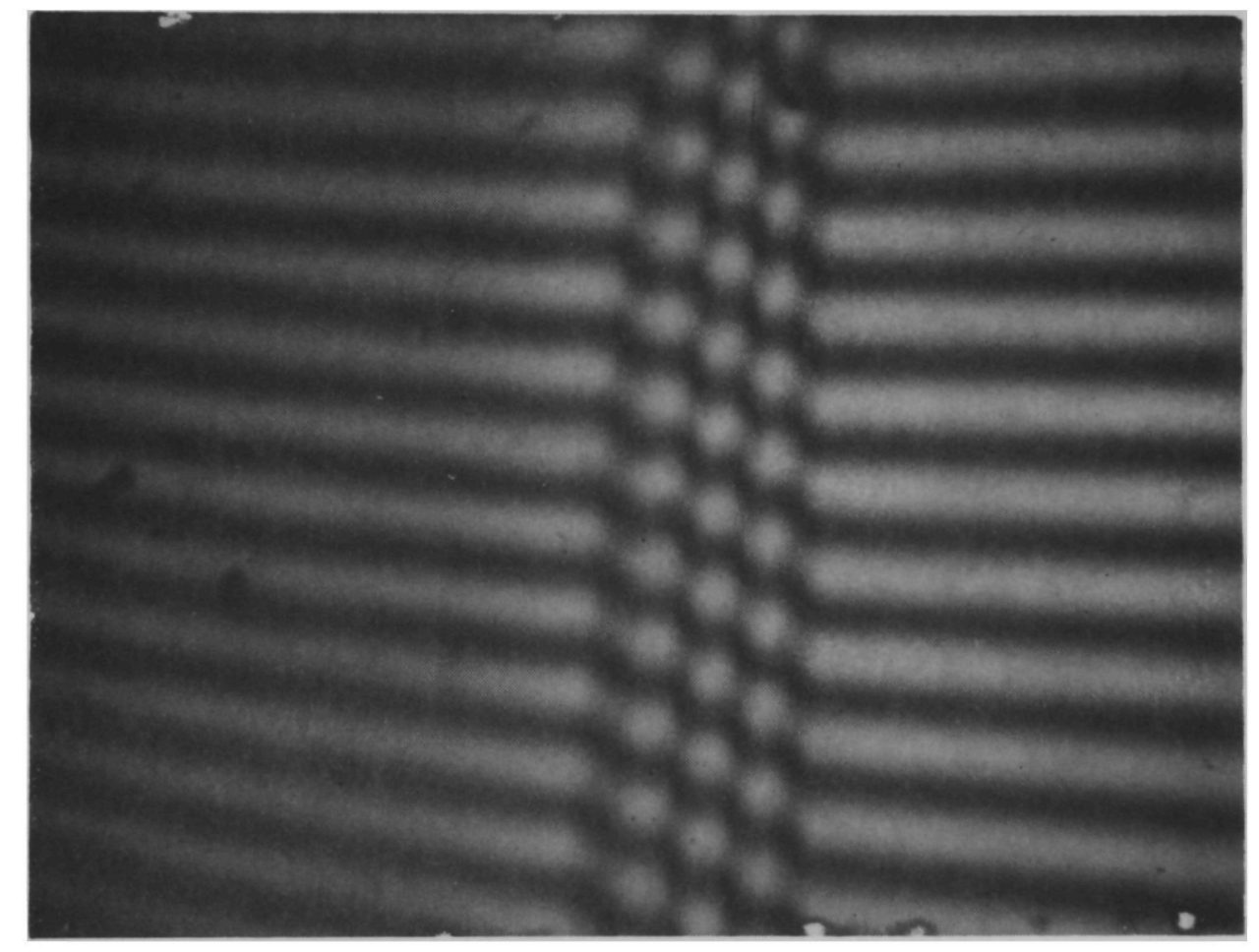

Figure 11. Typical interference pattern used for dielectric thin film thickness measurement. 
different from that of the pilot slice. In order to check the validity of this conjecture, several pilot slices were distributed across the substrate surface and sputtered for a period of three hours from a barium titanate target. It was found that the sputtering was not, in fact, uniform. Random variations of as much as $60 \%$ were obtained in the film thicknesses.

\section{B. Substrate Evaluation}

The first substrate material which was examined was high purity aluminum cut in 5/8 inch diameter discs from Reynolds Aluminum Alclad 1100 aluminum sheets, 0.012 inch thick, using a punch similar to the one used by the NASA Manned Spacecraft Center for cutting the discs for their silver-silver chloride electrodes. The 5/8 inch diameter was chosen for its compatibility with the geometry of NASA electrode housings; aluminum was chosen for its electrical properties and for its low cost. The discs were polished to a mirror finish before they were used as sputtering substrates in order to provide a flat, scratch free surface. It was not possible to obtain a completely scratch free surface even after polishing with 0.5 micron sized alumina granules; however, the scratches were not the major objection to the use of aluminum. It was found that, during the deposition of the dielectric, the discs heated sufficiently so that they deformed. After the deposition was complete and the discs had cooled, they assumed their original shapes, cracking the rigid thin film of dielectric material. When these discs were tested as electrodes, skin electrolytes filled the cracks, providing a shorting path between the skin and the conductive aluminum substrate. 
During this work, highly polished pieces of silicon were used as pilot slices for the determination of sputtered thickness. The quality of the film was noted to be good; therefore, tests were made to determine if silicon might be a suitable substrate. Squares of approximately $1 \mathrm{~cm}^{2}$ in surface area were scribed out of silicon slices. The choice of square geometry was dictated by the lack of specialized equipment required for cutting circles. The original slices had been previously Blanchard ground to a very high polish and degree of flatness (they were, in fact, substrates for epitaxial deposition). The material was approximately one ohm-cm, n-type and was about 0.010 inch thick.

Before being placed in the sputtering chamber, the squares were degreased for fifteen minutes in a boiling methanol/xylene $(1: 1)$ solution. They were then rinsed with deionized water and immersed in hot concentrated sulfuric acid for fifteen minutes, rinsed again in deionized water and immersed in hot nitric acid for fifteen minutes, and then rinsed in deionized water. A final rinse was made in trichlorethylene, after which they were dried in air. Sputtering was performed in an argon-oxygen mixture at around $25 \mathrm{\mu m} \mathrm{Hg}$ (except for the silicon dioxide deposition, which was performed in argon) to prevent reduction of the oxides to their metals. Films up to $50,000 \AA$ were obtained with no cracking of the dielectric layer.

\section{Impedance Transformer}

The circuit chosen for this work is shown in Figure 12. The simplicity of the unity gain configuration noted. This is, of course, highly desirable when space is limited, as it is in the insulated 


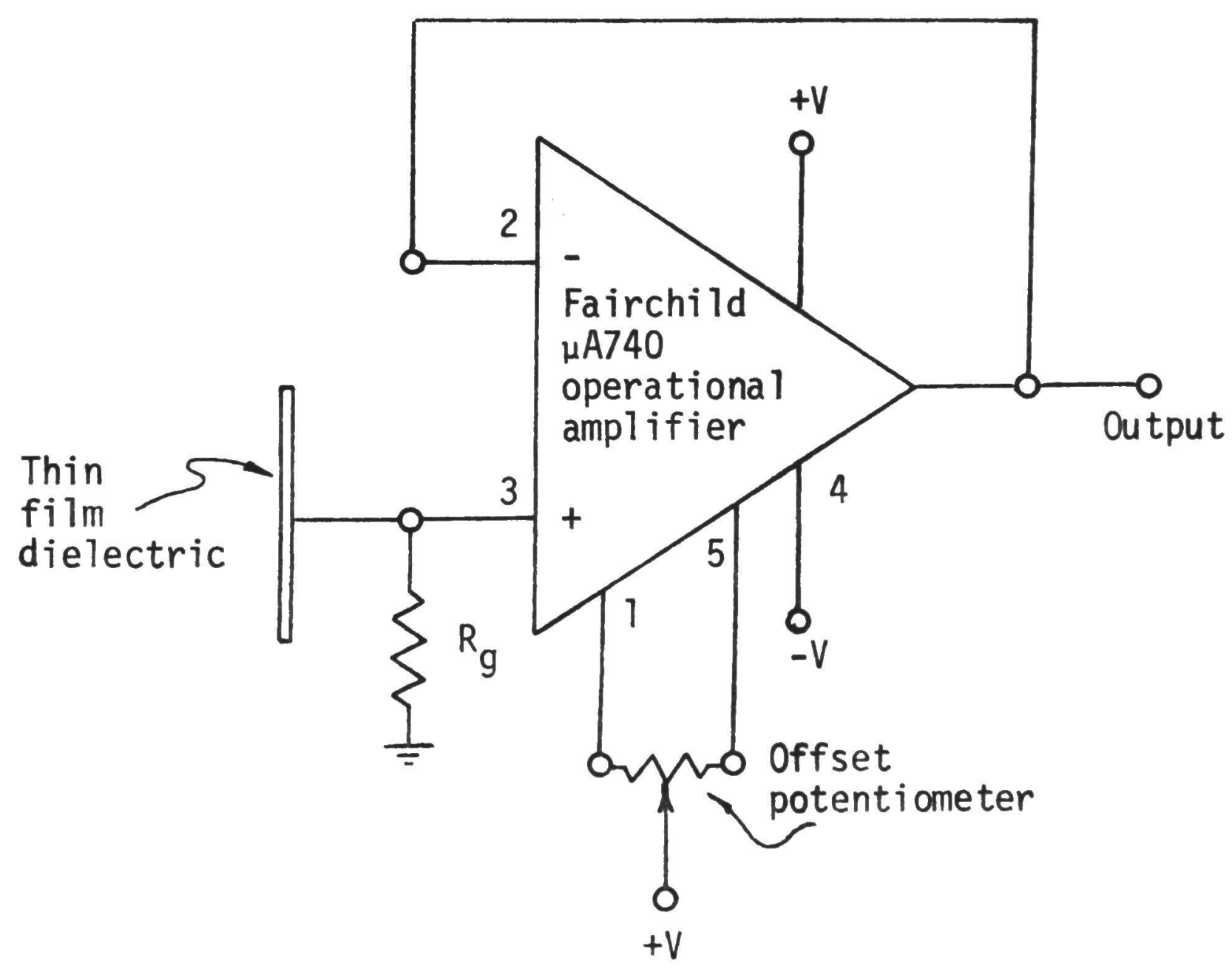

Figure 12. Circuit diagram for insulated ECG electrode. 
ECG electrode. Several standard operational amplifiers were considered but the Fairchild $\mu A 740$ seemed to have the best characteristics.

It was mentioned earlier that the operational amplifier must have a very large input impedance, a very large open loop gain, and a very small output impedance. In addition to these very important features, some other constraints were specified. If the operational amplifier requires external frequency compensation, as many do, the simplicity of the unity gain configuration is lost in a maze of lead and lag circuits. It was therefore specified that the operational amplifier should be internally compensated, requiring no external circuitry. Since the electrode was to be small in size, the operational amplifier packaging had to be compatible with simple miniaturization. The dual-in-line package was consequently eliminated from consideration.

One further characteristic is perhaps the most important reason for the choice of amplifiers. Consider the effect of input bias current, which is present to some degree in all direct coupled operational amplifiers. This current must flow through the input resistor $\mathrm{R}_{\mathrm{g}}$. Because of the nature of the RC coupling of the insulated ECG electrode, it is necessary that $R_{g}$ be quite large, as pointed out earlier. If $R_{g}$ is chosen to be 100 megohms and the input bias current is 10 nanoamperes, then an input voltage of 1 volt would be obtained and seen as a dc offset voltage at the output. While most operational amplifiers are designed so that an output offset can be nulled, they are not designed for compensation of such magnitudes. It was therefore necessary to specify that the operational amplifier must have a low input bias current in order to maintain a high value of $R_{i n}$. 
The specifications of the $\mu A 740$ meet all these requirements. It is a high performance FET input operational amplifier constructed by the planar-epitaxial process. The intrinsic input impedance due both to the FET input and internal feedback is typically $10^{12}$ ohms. The open loop gain is typically in the neighborhood of $5 \times 10^{5}$ or $114 \mathrm{~dB}$, while the intrinsic output impedance is nominally 75 ohms. In addition to these excellent characteristics, it is internally frequency compensated and comes in a T0-99 package which is quite suitable in size. The final parameter of interest here is the input bias current which is typically 100 picoamperes.

In order to be completely assured of these specifications and of the suitability of the amplifier, some measurements were performed on four separate $\mu A 740$ operational amplifiers selected at random. The input impedance was measured first. A suitable $R_{g}$ had to be selected for each device. Two amplifiers were each equipped with a 200 megohm $\pm 10 \%$ resistor consisting of two 100 megohm $\pm 10 \%, 1 / 8$ watt resistors in series. The other two amplifiers were each equipped with a 22 megohm $\pm 10 \%, 1 / 4$ watt resistor which had been suitably filed down to a resistance between 100 and 200 megohms. The amplifiers were completely wired into their proper configuration and into the electrode housings (discussed later) so that the actual electrode configuration could be evaluated in addition to evaluating the operational amplifier properties. The measurement was performed in two ways using the circuits of Figures 13a and 13b. Using the voltage divider, the input impedance was obtained from equation (9). 


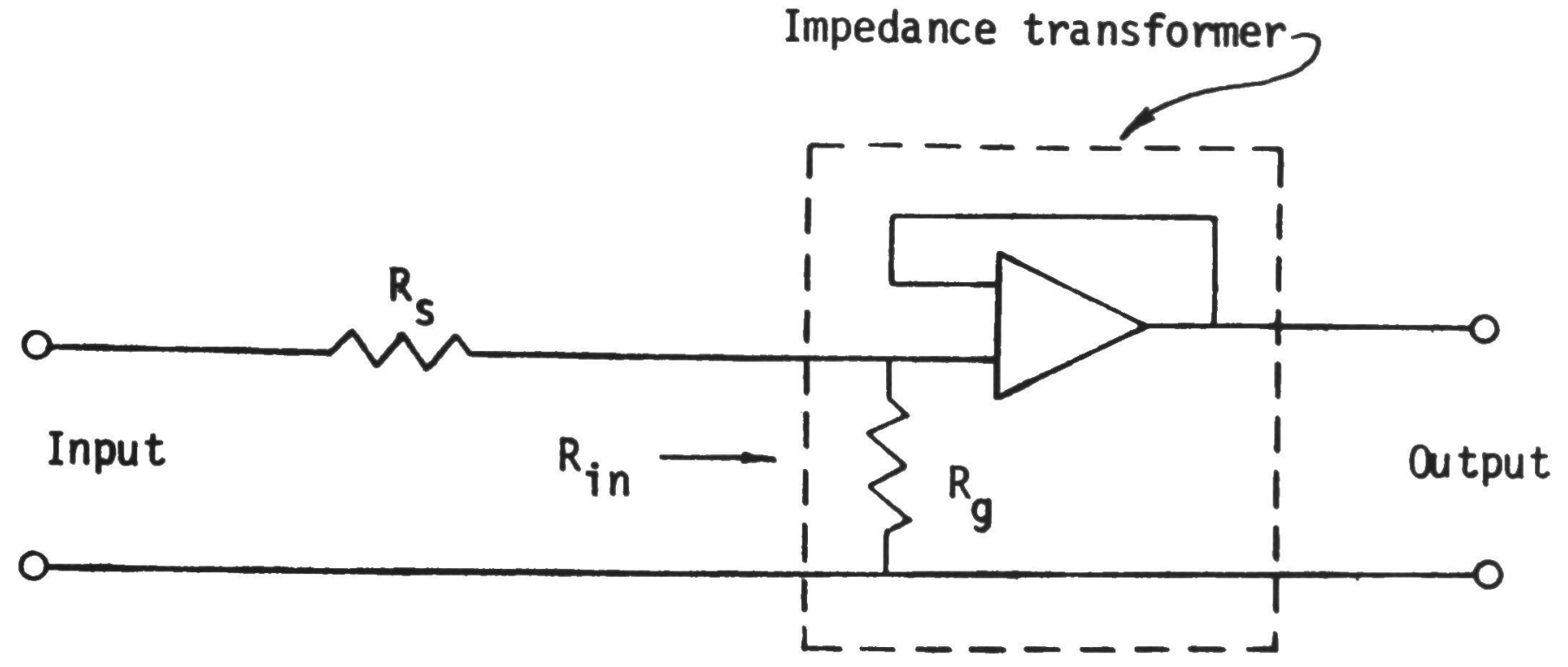

$13 a$

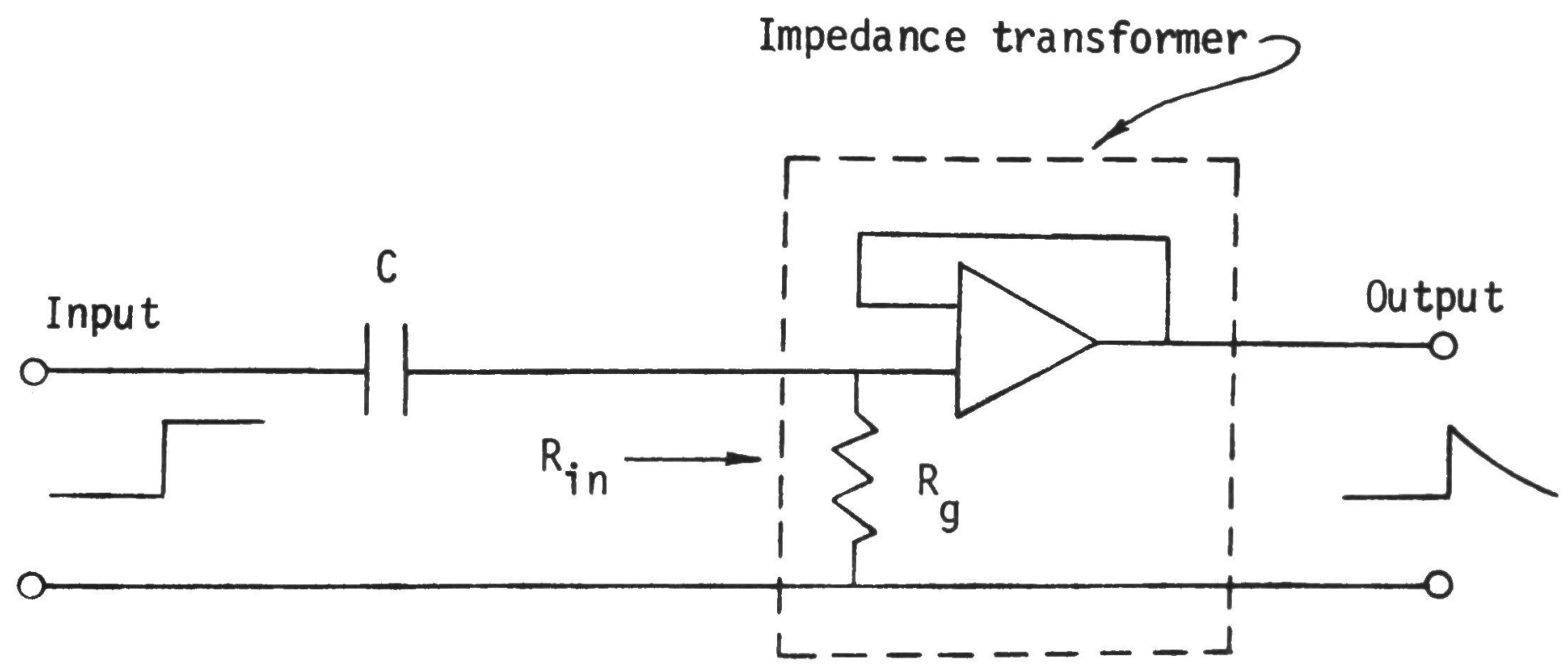

$13 b$

Figure 13. Circuits used to measure impedance transformer input impedance. 


$$
R_{\text {in }}=\frac{R_{s} V_{0}}{V_{i}-V_{0}}
$$

The assumption that the gain of the unity gain configuration was indeed unity was made and later confirmed. The second circuit was used both as confirmation of the voltage divider measurement and as a basis for electrode capacitance and frequency response measurements discussed later. $R_{\text {in }}$ is found in this measurement from equation (10),

$$
R_{\text {in }}=\frac{\tau}{C}
$$

where $\tau$ is the time constant associated with the output exponential decay.

The performance of these measurements was straightforward and the results are given in Table 2 for comparison. The values obtained for the input impedance from the measurement of the time constant illustrated in Figure 13b compare well with those obtained using the circuit of Figure 13a. The values obtained appeared to be equal to $R_{g}$, as was expected from equation (8).

The next measurement performed was on the amplifier-impedance transformer gain and bandwidth, and was made using the circuit of Figure 14. $R_{g}$ for each of the same four amplifiers used previously remained unchanged. The $100 \mathrm{kilohm}-10 \mathrm{kilohm}$ voltage divider was provided so that the signal generator could operate at its optimum output level and not overdrive the input of the amplifier. The second $10 \mathrm{kilohm}$ resistor merely provided additional generator to amplifier isolation and served as a convenient location on the circuit breadboard for easy attachment of an oscilloscope probe. The input signal 
TABLE 2

MEASURED ELECTRODE IMPEDANCE TRANSFORMER PARAMETERS

\begin{tabular}{|c|c|c|c|}
\hline $\begin{array}{c}\text { Electrode Impedance } \\
\text { Trans former Number }\end{array}$ & $\begin{array}{c}\text { Rin From } \\
\text { Figure 13a } \\
(\mathrm{M} \Omega)\end{array}$ & $\begin{array}{c}\text { Rin From } \\
\text { Figure 13b } \\
(\mathrm{M} \Omega)\end{array}$ & $\begin{array}{c}\text { Output } \\
\text { Impedance } \\
(\Omega)\end{array}$ \\
\hline 1 & 200 & 205 & $<5$ \\
2 & 200 & 205 & $<5$ \\
3 & 135 & 140 & $<5$ \\
4 & 110 & 115 & $<5$ \\
\hline
\end{tabular}

\begin{tabular}{|c|c|c|}
\hline $\begin{array}{c}\text { Electrode Impedance } \\
\text { Transformer Number }\end{array}$ & $\begin{array}{c}\text { Midband } \\
\text { Gain }(\mathrm{V} / \mathrm{V}) \\
\text { At } 1 \mathrm{KHz}\end{array}$ & Bandwidth \\
\hline 1 & 0.998 & $\mathrm{dc}-600^{+} \mathrm{KHz}$ \\
2 & 1.000 & $\mathrm{dc}-600^{+} \mathrm{KHz}$ \\
3 & 1.000 & $\mathrm{dc}-600^{+} \mathrm{KHz}$ \\
4 & 1.000 & $\mathrm{dc}-600^{+} \mathrm{KHz}$ \\
\hline
\end{tabular}




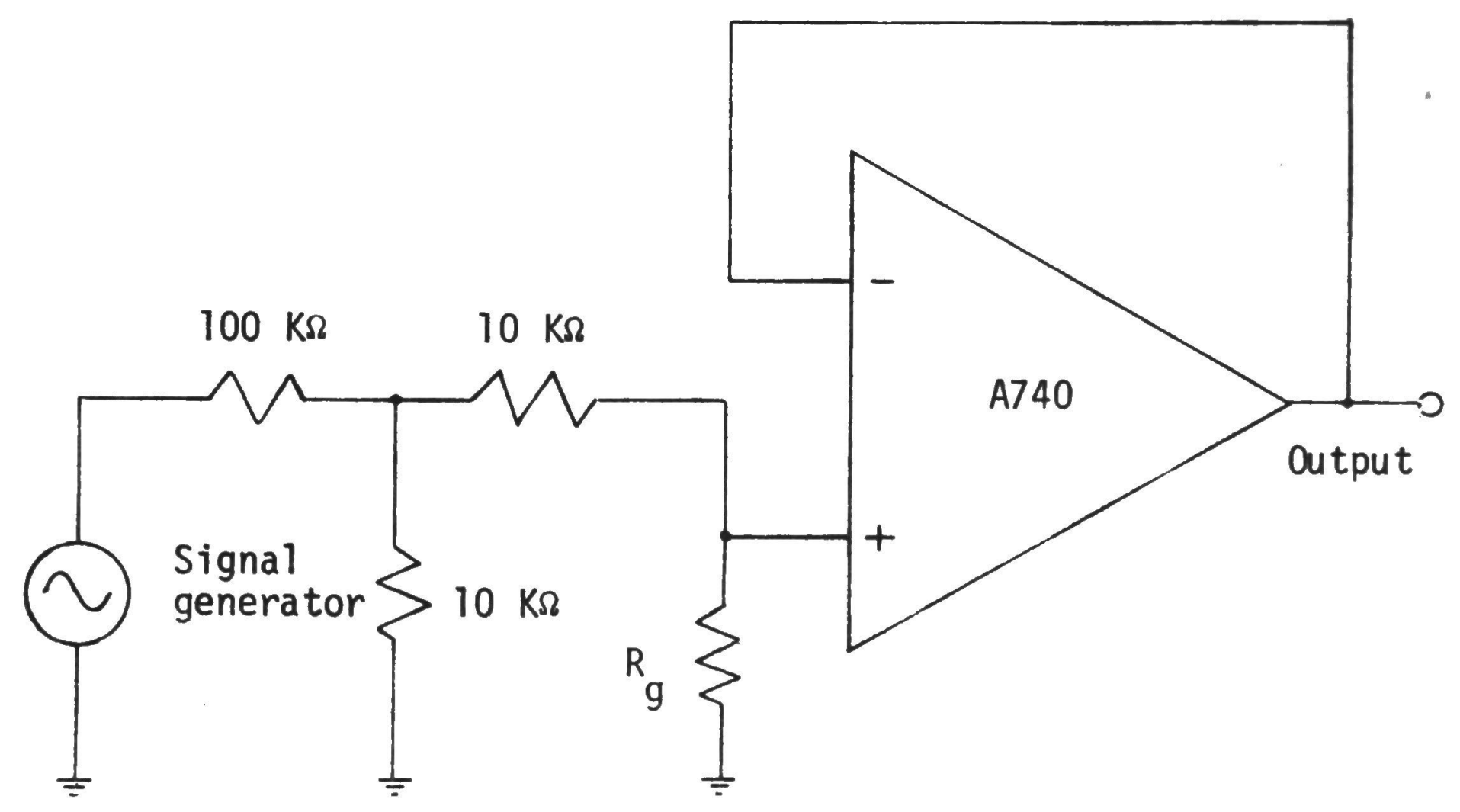

Figure 14. Circuit used to measure impedance transformer gain and bandwidth. 
frequency was varied while the output signal was compared with it in both magnitude and phase. Each circuit was found to have voltage gain of unity which was quite flat from dc up to a frequency of $20 \mathrm{KHz}$. From $20 \mathrm{KHz}$ up to $600 \mathrm{KHz}$ the response showed as much as $+2 \mathrm{~dB}$ of peaking. No $-3 \mathrm{~dB}$ point could be found between $\mathrm{dc}$ and $600 \mathrm{KHz}$.

The output impedance was not specifically measured, but an upper bound was obtained by a very simple measurement. A dc voltage was applied to the input and the open circuit output voltage was measured. Without changing the input, a load resistance of 510 ohms was attached and the output was again measured. No difference was noted in the output level in any of the four amplifiers tested. Since the accuracy of the measurement was within $1 \%$, it was inferred that the upper bound of the output impedance was 5 ohms. It was not considered desirable to allow the amplifier to drive any smaller load, since some damage might result to these impedance transformers, which were, in fact, the same ones to make the first four insulated ECG electrodes. There is little reason to distrust the impedance value obtained from equation (7), which is $1.5 \times 10^{-4}$ ohms, using $A_{0}(\omega)=5 \times 10^{5}$. The nature of the connections makes this number somewhat unrealistic; however, the output impedance transformer is sufficiently small so that the circuit is quite acceptable.

The input bias current was not directly measured, but output offset voltages of only a few millivolts were observed and easily nulled. One additional item of information was obtained. Circuit operation was satisfactory over a supply voltage range between \pm 3 volts and \pm 22 volts, which provides an extensive choice in power supply design. At 
the supply level of \pm 5 volts chosen in the electrode evaluation, a supply drain of 7 milliamperes was measured.

During the course of electrode evaluation it was felt that at least one other operational amplifier should be examined for its compatibility with the insulated ECG electrode system design. While the $\mu A 740$ with its FET input met all requirements very well, its cost was high. Another Fairchild operational amplifier, the $\mu A 741$, was chosen for evaluation. The $\mu A 741$ is a bipolar input, high performance, monolithic operational amplifier with almost identical characteristics to the $\mu \mathrm{A740}$; however, its cost is only $6 \%$ of the cost of the $\mu A 740$. In the unity gain configuration, the $\mu A 741$ has an input impedance of around 400 megohms, which, although considerably less than that of the $\mu A 740$, is still acceptable. It failed to perform satisfactorily, however, because of the design factor mentioned earlier: input bias current. This current in the $\mu A 741$ is typically 80 nanoamperes as opposed to the 0.1 nanoampere input bias current of the $\mu A 740$. As demonstrated in the previous example, this level would require a significant reduction in $R_{g}$ and, therefore, in input impedance in order to reduce the dc offset voltage to an acceptable level. The alternative is the design of compensating circuits or alteration of the power supply arrangement. This procedure would have to be done individually for each electrode and would require a significant amount of extra labor in the production of the insulated ECG electrodes. In addition to this, the compensated $\mu A 741$ would still be far more sensitive to changes in amplifier characteristics than the $\mu \mathrm{A} 740$. The $\mu \mathrm{A} 741$ and similar operational amplifiers were consequently eliminated from further consideration. 
D. The Insulated Electrode Assembly

The insulated dielectric square, grounding resistor $R_{g}$, and the A740 operational amplifier were all incorporated into a single unit using the standard NASA Manned Spacecraft Center paste electrode housing. This housing, which is $11 / 8$ inch in diameter and $1 / 4$ inch deep, easily accomodates the electronics, resistor, and wiring, as well as providing a compact arrangement. A hole was drilled into the back of the housing to allow the snug insertion of the $\mu$ A740 T0-99 case. The arrangement is illustrated in Figure 15. To assure adhesion, $3 \mathrm{M}$ Scotchcast brand electrical resin was spread across the casehousing interface. Following the insertion of the operational amplifier, six Belden Teflon insulated number 29 AWG single strand wires were inserted into the housing through a small hole in the side, as shown in Figure 15. Each wire was wrapped around its proper $\mu A 740$ pin (Figure 16) and lightly soldered. It was necessary to have the grounding resistor inside the housing; therefore, it was covered by Alpha Electronic Wire irradiated polyolefin, 1/16 inch diameter shrink tubing, and soldered into place. The pins were then bent back into the housing cavity so that no protrusion past the front surface occurred. A top view of the electrode housing design is shown in Figure 16.

The main objective of this work was the evaluation of the dielectric squares and not the electrode electronics. For this reason, and because of cost, it was decided that it was desirable to change dielectric squares without disturbing the electronics or housing. The following scheme was adopted. A disc of clear plastic, 1/8 inch thick and 


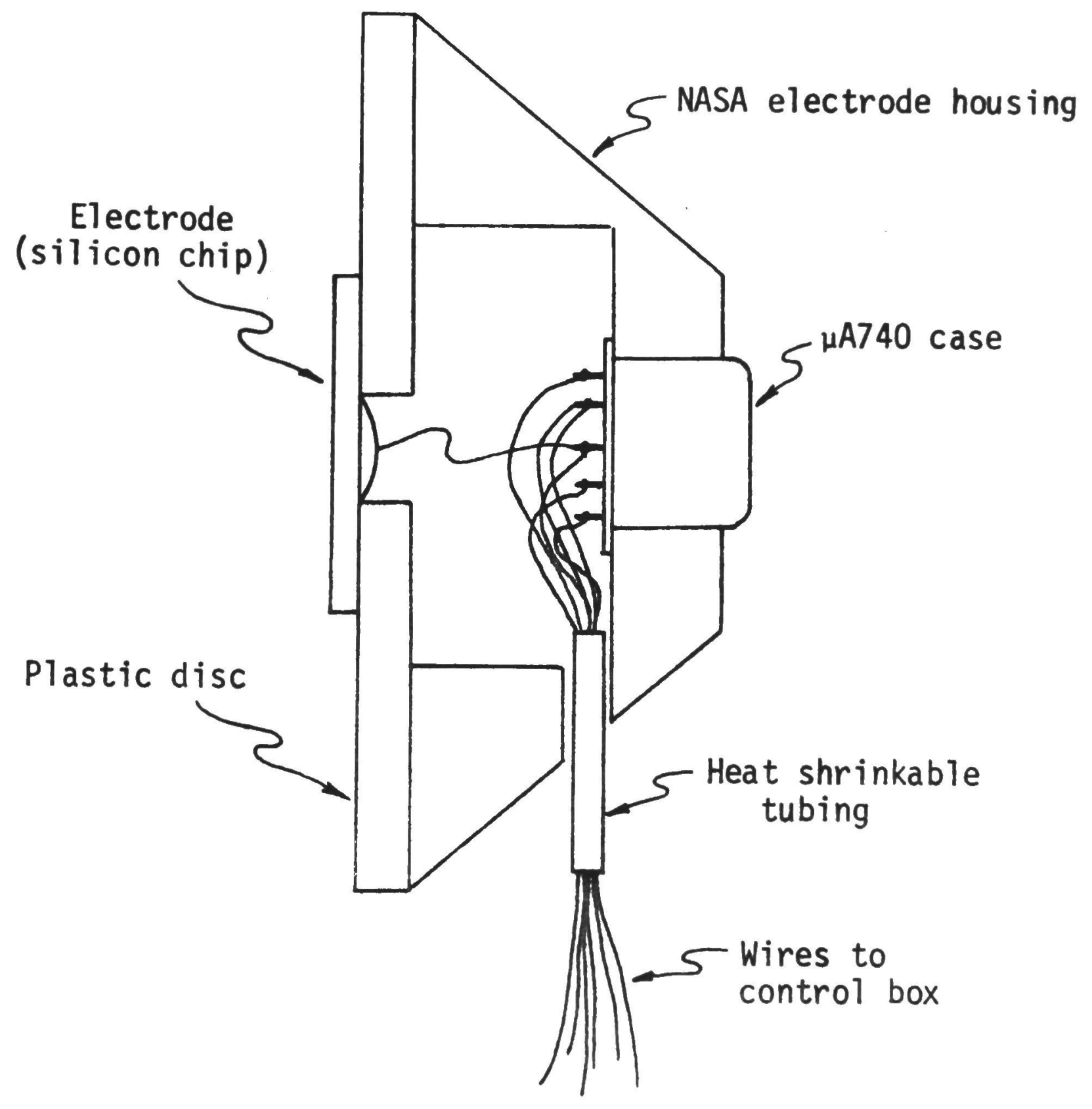

Figure 15. Side view of insulated ECG electrode. 


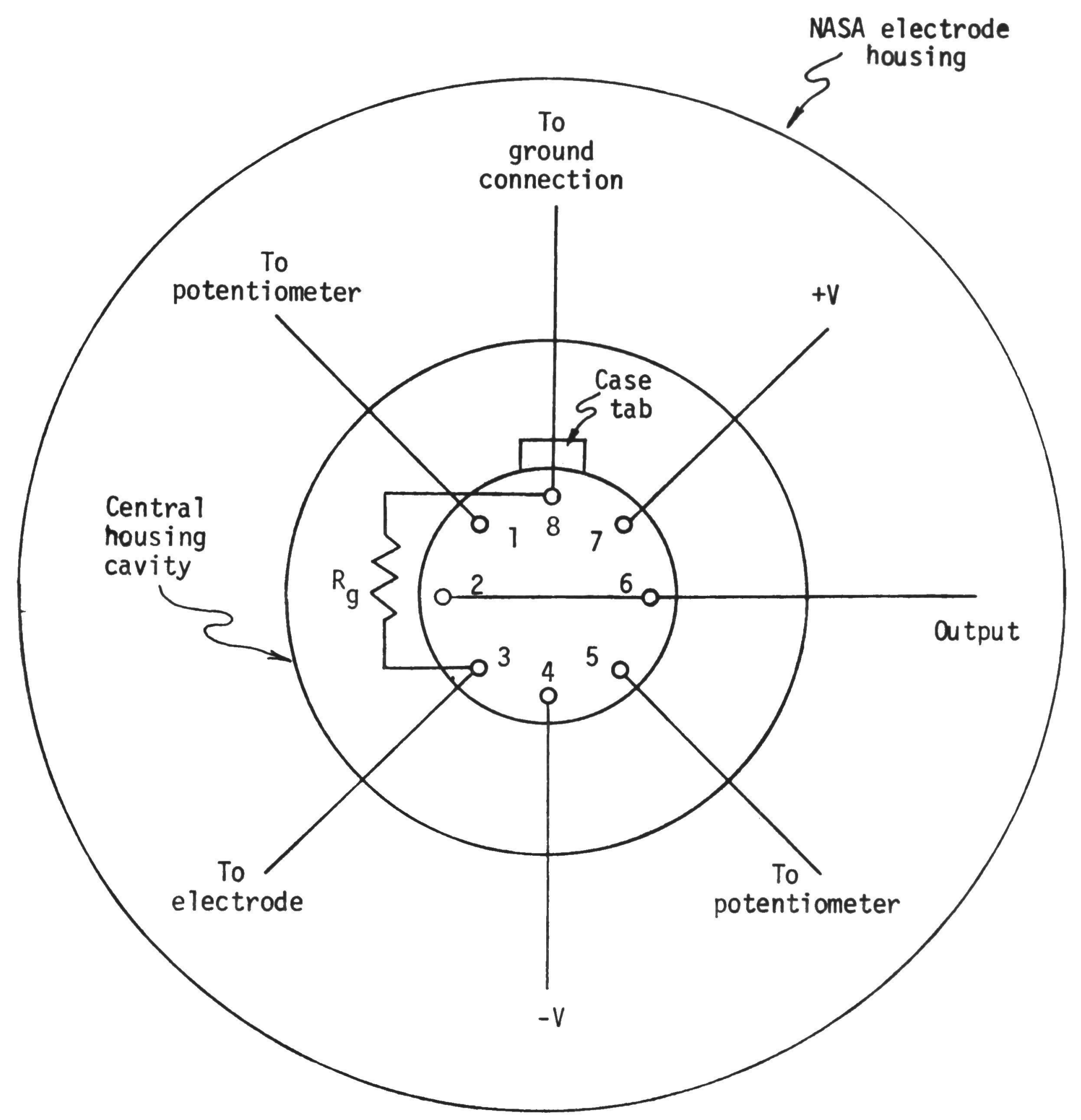

Figure 16. Top view of insulated ECG electrode. 
$11 / 16$ inch in diameter (approximately that of the housing) was cut with a hole saw, which also drilled a small hole in the center of the disc. A single wire (the same as above) was secured to the back of the dielectric square using the same conductive epoxy that was employed in the sputtering target fabrication. The chip was then fastened to the plastic disc with Scotchcast electrical resin, the wire passing through the center hole. Sufficient resin was used not only to assure a secure bond but also to cover the edges of the dielectric square. This eliminated any possible contact between the skin and the substrate, avoiding skin-to-substrate shorts.

Connecting the capacitor discs to the impedance transformer now merely required soldering the protruding wire to pin 3 of the $\mu A 740$. The plastic disc was held firmly to the face of the electrode housing with double sided adhesive tape, the same which was used to attach the electrode to the skin. Changing the electrode capacitor discs was simply a matter of detaching the disc from its tape connection and unsoldering the single wire. This procedure was performed well in excess of 100 times on one electrode without damage to the operational amplifier or to any capacitor disc used. Figure 17 is a photograph of the housing before the plastic disc has been affixed, and Figure 18 is a similar photograph with both an unassembled and an assembled electrode for comparison. The five cent piece is shown for relative size.

Some external electrode apparatus was required. The six wires mentioned earlier were connected to various portions of a control box. In order to protect and join the wires into a single cable, they were covered with $1 / 8$ inch shrink tubing. No cable shielding was provided 


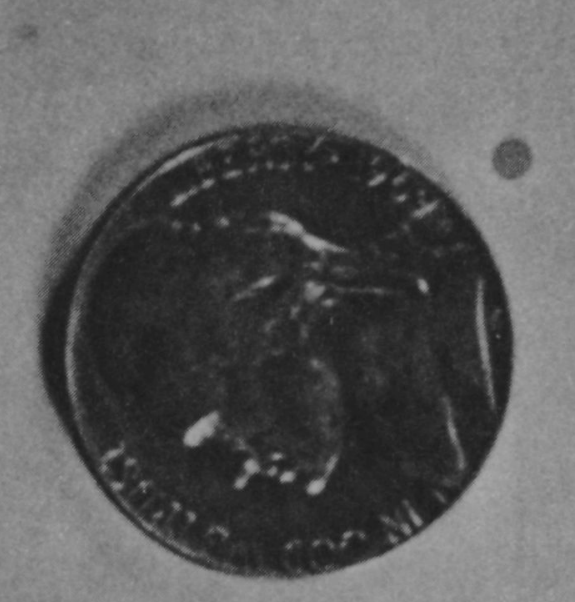



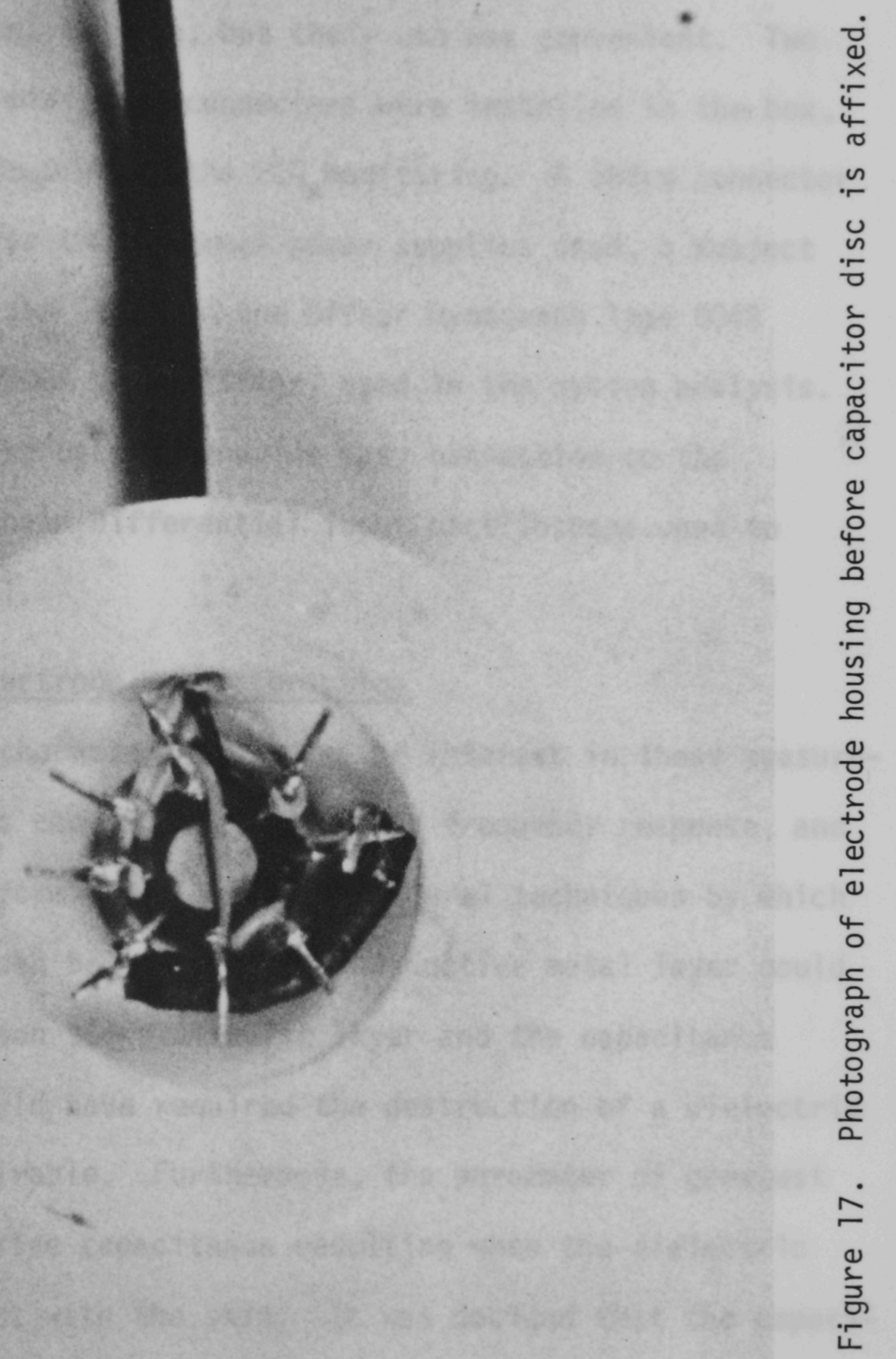
and the electrode performance indicated later that none was required. The control box housed the dc offset potentiometers and various connectors. The potentiometers were not absolutely required since there was little offset voltage, but their use was convenient. Two ITT Cannon seven pin miniature connectors were installed in the box, one for each electrode used in the ECG monitoring. A third connector provided connection for the external power supplies used, a subject body grounding wire, and leads to the Offner Dynograph Type 504B recorder, with Type 9806A preamplifier, used in the system analysis. Two BNC connectors were used to provide easy connection to the Tektronix R5030 dual-beam differential input oscilloscope used to monitor the ECG signal.

\section{E. Measurement of Electrode Characteristics}

Three electrode characteristics were of interest in these measurements: capacitor disc capacitance, electrode frequency response, and overall electrode performance. There are several techniques by which the disc capacitance can be measured. A corductive metal layer could have been deposited upon the dielectric layer and the capacitance measured, but this would have required the destruction of a dielectric disc, which was undesirable. Furthermore, the parameter of greatest interest is the effective capacitance resulting when the dielectric thin film makes contact with the skin. It was decided that the capacitance measurement should be made with the electrode in place on a subject. Figure 19 illustrates the circuit used to obtain the frequency response of the electrode-subject system; this measurement is 


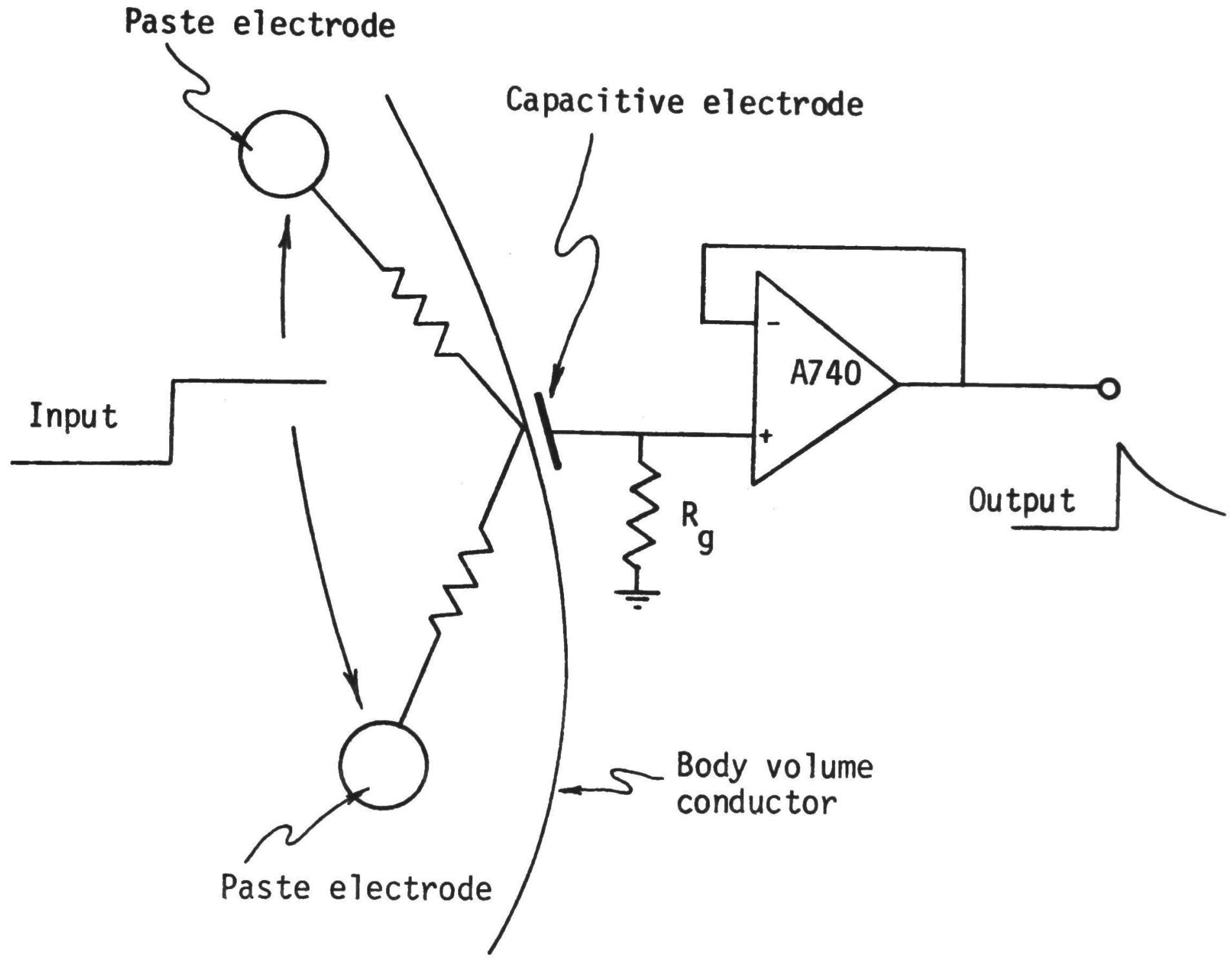

Figure 19. Circuit used to obtain frequency response of electrode-subject system. 
similar to that used to obtain the input impedance of the impedance transformer. Since $R_{i n}$ had already been obtained for each of the electrodes, and since the exponential time constant could easily be measured, the effective capacitance could be calculated from $C=\frac{\tau}{R_{i n}}$. This measurement also allows a simple specification of the lower frequency $-3 \mathrm{~dB}$ point of the frequency response of the system. Since $\omega_{0}=\frac{1}{\tau}$ corresponds to the first pole of the electrode transfer function specifying the lower cutoff frequency, this point is easily calculated from $f_{0}=\frac{1}{2 \pi \tau}$.

Standard paste electrodes acted as contacts to which a step input voltage was applied. The output response was plotted on the direct writing recorder previously described, which was also used to obtain the ECG data discussed later. The output was also monitored on the oscilloscope. A typical system response is shown in Figure 20. The dielectric thin film on the capacitor disc is tantalum pentoxide, around $6000 \AA$ thick, but the response is typical of that obtained with other thicknesses and dielectrics.

It is clear from the nature of charging characteristics that the insulated ECG electrode is capacitively coupled; however, it is not apparent from the curve whether the response is a simple exponential or if it is more complex in nature. In order to be certain that the response was exponential, the data were replotted semilogarithmically. For most electrodes with medium to fast decay times, the plot indicated that the decay was that of a single exponential. Upon plotting the data associated with longer decay times, a second long time constant was discovered. The second time constant (approximately 15 seconds in 


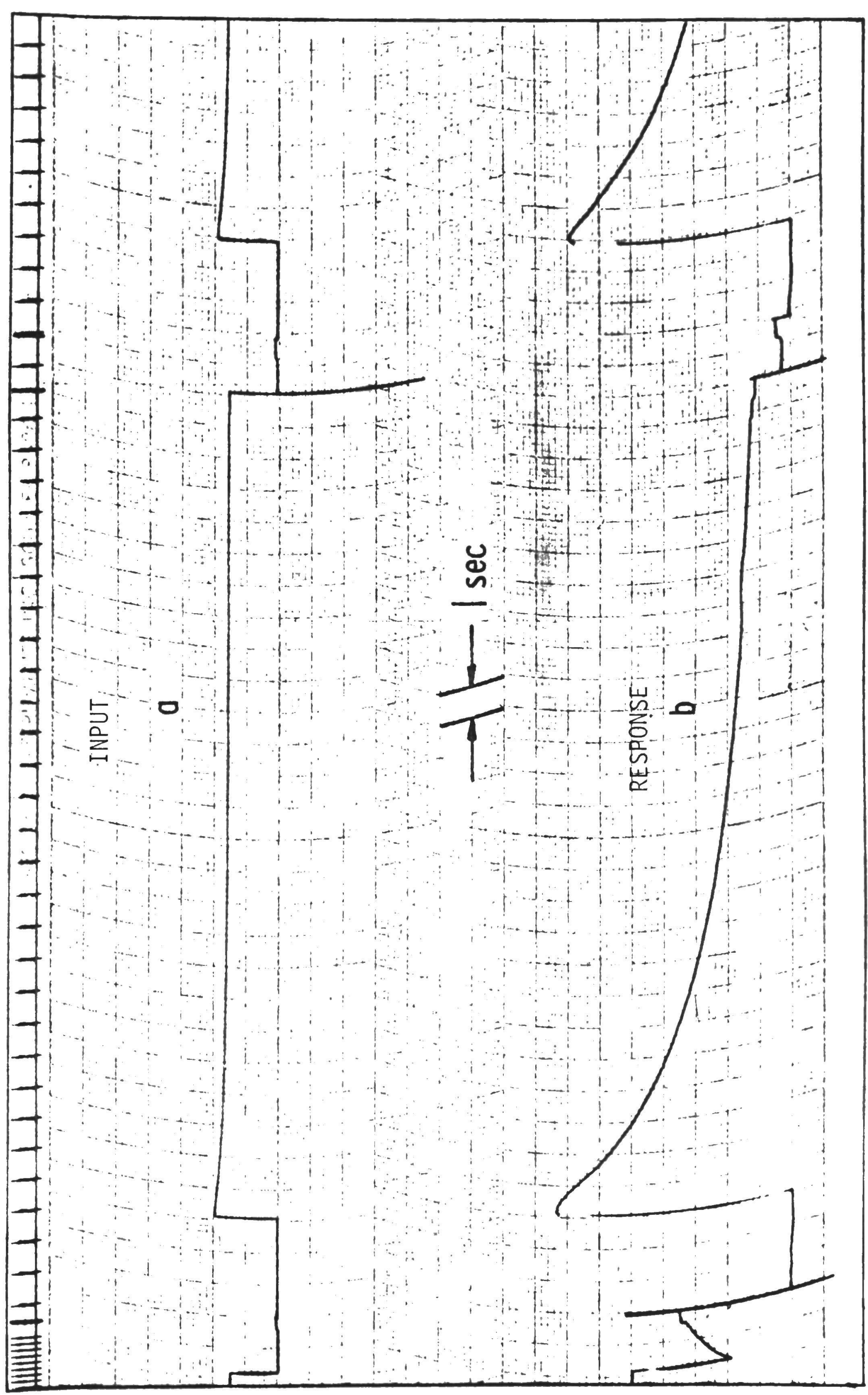

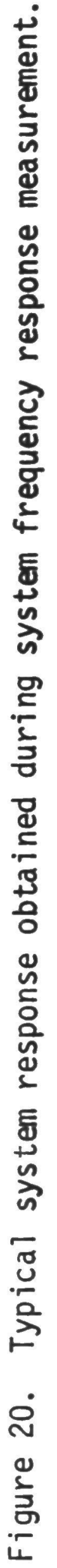


duration) was attributed to an unknown decay of either mechanical or electrical nature in the recorder, which appeared despite direct coupling. The long decay can be noted in the upper curve of Figure 20, which corresponds to the step voltage input applied to the paste electrodes. The second time constant was of sufficient length so that it did not interfere significantly with the acquisition of the decay data for the electrode system. It was assumed that the RC charging time corresponded to the time constant of the measured data so that the electrode capacitance and lower cutoff frequency for each electrode was obtained from the previous expressions.

Typical values calculated from the measured constants are listed in Table 3. The calculated value listed is that obtained by using the expression, $\frac{C}{A}=\frac{\varepsilon}{d}$, and $f_{0}$ is calculated from the measured time constant. Calculated and measured values of specific capacitance differ, and differences were also found among measured specific capacitances at a given film thickness and for a particular dielectric material.

The differences between specific capacitances are probably the result of two factors. As previously discussed, the uniformity of the thickness of the sputtered thin films was not very good. The thickness of the film varied with the position of the silicon substrate in the sputtering chamber. The pilot slices were placed as close as possible to the sputtered substrates; however, uniformity could not be guaranteed within $20 \%$ even across the pilot slice. Although good resolution was obtained with the microscope, the exact thickness of the film on the substrates could not be specified within the desired accuracy. The time constant could vary from sample to sample within 
TABLE 3

MEASURED VALUES OF THE LOWER CUTOFF FREQUENCIES FOR THE ELECTRODE SYSTEM AND MEASURED AND CALCULATED VALUES OF SPECIFIC CAPACITANCE FOR THE DIELECTRIC FILMS

\begin{tabular}{|c|c|c|c|c|c|}
\hline \multirow{2}{*}{$\begin{array}{l}\text { Material } \\
\text { (Nominal relative bulk } \\
\text { dielectric constant) }\end{array}$} & \multirow{2}{*}{$\begin{array}{l}\text { Film } \\
\text { Thickness } \\
\text { ( }) \\
(A)\end{array}$} & \multirow{2}{*}{$\begin{array}{l}\text { Electrode } \\
\text { Area } \\
\left(\mathrm{cm}^{2}\right)\end{array}$} & \multirow[t]{2}{*}{$\begin{array}{c}f_{0} \\
(H z)\end{array}$} & \multicolumn{2}{|c|}{$\begin{array}{c}\text { Capacitance Per } \\
\text { Unit Area }\end{array}$} \\
\hline & & & & $\begin{array}{c}\text { Measured } \\
\left(\mu \mathrm{F} / \mathrm{cm}^{2}\right)\end{array}$ & $\begin{array}{l}\text { Calc. } \\
\left(\mu \mathrm{F} / \mathrm{cm}^{2}\right)\end{array}$ \\
\hline \multirow[t]{3}{*}{$\begin{array}{l}\mathrm{BaTiO}_{3} \\
(1500)\end{array}$} & $\begin{array}{l}47000 \\
47000\end{array}$ & $\begin{array}{l}0.81 \\
0.80\end{array}$ & $\begin{array}{l}0.032 \\
0.021\end{array}$ & $\begin{array}{l}0.044 \\
0.064\end{array}$ & $\begin{array}{l}0.29 \\
0.29\end{array}$ \\
\hline & $\begin{array}{l}24000 \\
24000\end{array}$ & $\begin{array}{l}0.81 \\
0.76\end{array}$ & $\begin{array}{l}0.024 \\
0.032\end{array}$ & $\begin{array}{l}0.058 \\
0.047\end{array}$ & $\begin{array}{l}0.57 \\
0.57\end{array}$ \\
\hline & $\begin{array}{l}17000 \\
17000\end{array}$ & $\begin{array}{l}0.72 \\
0.76 \\
\end{array}$ & $\begin{array}{l}0.016 \\
0.014 \\
\end{array}$ & $\begin{array}{l}0.097 \\
0.11 \\
\end{array}$ & $\begin{array}{l}0.75 \\
0.75 \\
\end{array}$ \\
\hline \multirow[t]{3}{*}{$\begin{array}{l}\text { Ti02 } \\
(100)\end{array}$} & $\begin{array}{l}14500 \\
14500\end{array}$ & $\begin{array}{l}0.80 \\
0.81\end{array}$ & $\begin{array}{l}0.016 \\
0.018\end{array}$ & $\begin{array}{l}0.086 \\
0.079\end{array}$ & $\begin{array}{l}0.060 \\
0.060\end{array}$ \\
\hline & $\begin{array}{l}8800 \\
8800\end{array}$ & $\begin{array}{l}0.80 \\
0.79\end{array}$ & $\begin{array}{l}0.012 \\
0.013\end{array}$ & $\begin{array}{l}0.17 \\
0.11\end{array}$ & $\begin{array}{l}0.10 \\
0.10\end{array}$ \\
\hline & $\begin{array}{l}5900 \\
5900\end{array}$ & $\begin{array}{l}0.72 \\
0.63\end{array}$ & $\begin{array}{l}0.010 \\
0.013 \\
\end{array}$ & $\begin{array}{l}0.16 \\
0.14 \\
\end{array}$ & $\begin{array}{l}0.15 \\
0.15\end{array}$ \\
\hline \multirow[t]{3}{*}{$\begin{array}{r}\mathrm{Ta}_{2} \mathrm{O}_{5} \\
(25)\end{array}$} & $\begin{array}{l}47000 \\
47000\end{array}$ & $\begin{array}{l}0.80 \\
0.80\end{array}$ & $\begin{array}{l}0.11 \\
0.14\end{array}$ & $\begin{array}{l}0.013 \\
0.0099\end{array}$ & $\begin{array}{l}0.0048 \\
0.0048\end{array}$ \\
\hline & $\begin{array}{l}32000 \\
32000\end{array}$ & $\begin{array}{l}0.85 \\
0.85\end{array}$ & $\begin{array}{l}0.11 \\
0.080\end{array}$ & $\begin{array}{l}0.013 \\
0.017\end{array}$ & $\begin{array}{l}0.0068 \\
0.0068\end{array}$ \\
\hline & $\begin{array}{l}17000 \\
17000\end{array}$ & $\begin{array}{l}0.80 \\
0.80\end{array}$ & $\begin{array}{l}0.057 \\
0.072\end{array}$ & $\begin{array}{l}0.025 \\
0.020\end{array}$ & $\begin{array}{l}0.012 \\
0.012\end{array}$ \\
\hline \multirow[t]{3}{*}{$\begin{array}{l}\mathrm{SiO}_{2} \\
(4)^{2}\end{array}$} & $\begin{array}{l}32000 \\
32000\end{array}$ & $\begin{array}{l}0.85 \\
0.70\end{array}$ & $\begin{array}{l}1.0 \\
1.1\end{array}$ & $\begin{array}{l}0.0013 \\
0.0014\end{array}$ & $\begin{array}{l}0.0011 \\
0.0011\end{array}$ \\
\hline & $\begin{array}{l}20000 \\
20000\end{array}$ & $\begin{array}{l}1.0 \\
0.80\end{array}$ & $\begin{array}{l}0.64 \\
0.76\end{array}$ & $\begin{array}{l}0.0018 \\
0.0019\end{array}$ & $\begin{array}{l}0.0018 \\
0.0018\end{array}$ \\
\hline & $\begin{array}{l}4000 \\
4000\end{array}$ & $\begin{array}{l}0.75 \\
0.75\end{array}$ & $\begin{array}{l}0.17 \\
0.14\end{array}$ & $\begin{array}{l}0.0088 \\
0.10\end{array}$ & $\begin{array}{l}0.0088 \\
0.0088\end{array}$ \\
\hline
\end{tabular}


a single deposition run. The second factor contributing to inconsistancies is the nature of the contact made with the skin. The degree of contact made obviously will affect the capacitance and is a function of the skin to electrode pressure and other factors. The differences in measured specific capacitance for a given dielectric sputtering run are roughly consistent with the differences in film thickness which were undoubtedly present. The remainder of the inconsistency was probably the result of the nature of the skin-dielectric contact.

The values of specific capacitance obtained from the measurements and from calculations using the bulk dielectric constant of the dielectric sputtering target are quite different for the barium titanate and tantalum pentoxide films and cannot be easily explained. It is expected that the film dielectric constant will depend on the method of film deposition, and need not be the same as the bulk dielectric constant of the target. One additional factor may have also contributed to an alteration in dielectric constant. The sputtering was initially performed in an argon atmosphere, and reduction of the dielectrics to the metal occurred. Although sputtering in an argon-oxygen atmosphere restored the dielectrics, it cannot be stated that the bulk dielectric constants of the targets were not altered during the process.

A typical lead II electrocardiogram obtained using electrodes with titanium dioxide films approximately $6000 \AA$ thick is shown in Figure 21 . The same subject was monitored simultaneously using a set of paste electrodes as a reference. The results are typical of the data obtained with the other dielectric thin films with the exception of 


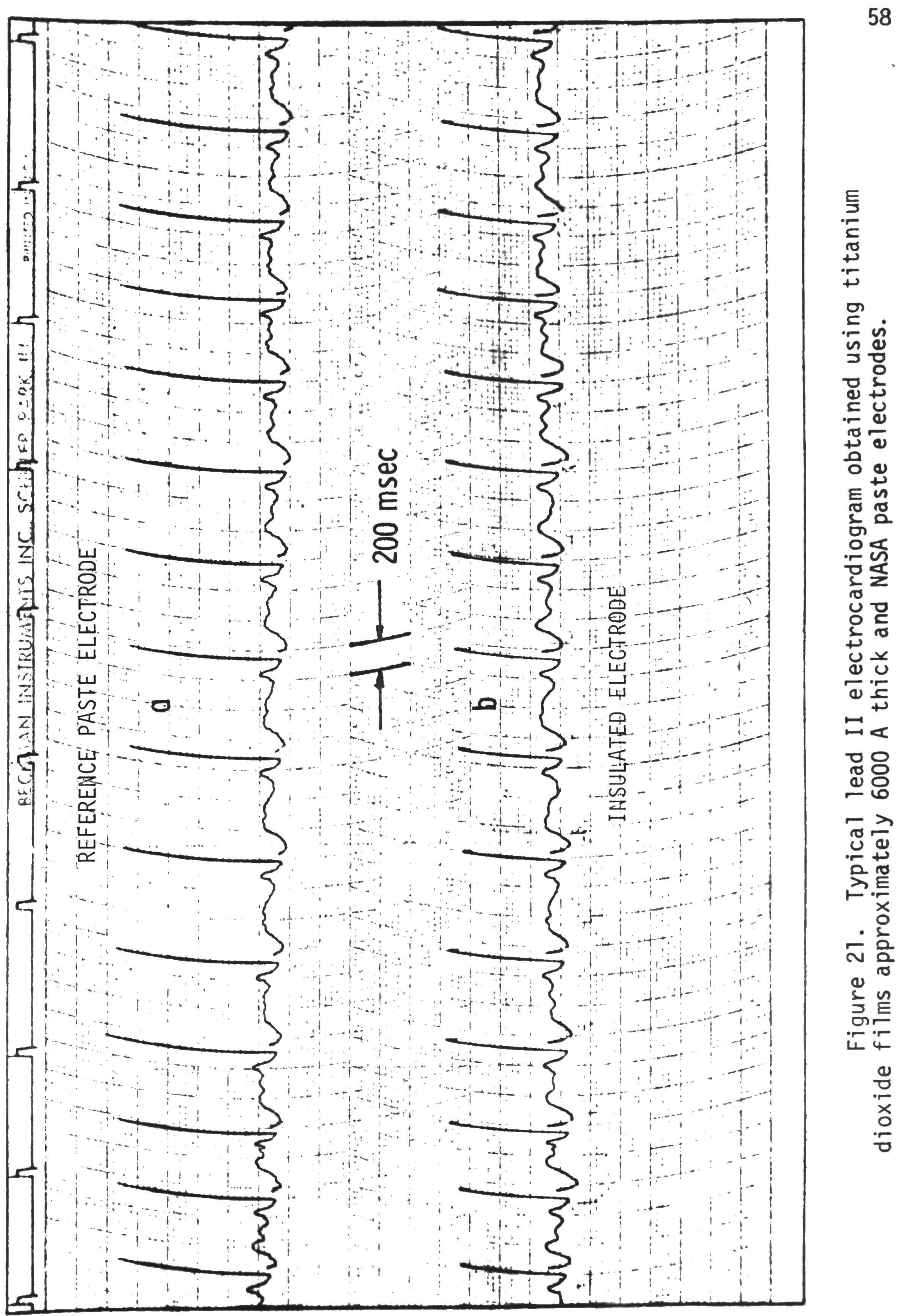


silicon dioxide, which is discussed below. The arrangement of the two sets of electrodes is shown in.Figure 22. A paste type ground electrode, not shown, is on the subject's right calf. There is no obvious difference in signal quality obtained by either set of electrodes. 60 cycle line noise and other spurious signals are absent for the insulated electrodes. A11 measurements were made in an extremely noisy environment and it was feared that the 3 foot long, six wire unshielded cable would pick up noise. The successful elimination of noise is attributed to three factors: uniformity of electrode transfer functions, $\mu A 740$ power supply line noise rejection, and the extremely low output impedance of the impedance transformer. The $\mu A 740$ is specified to have a power supply noise rejection ratio of 70 microvolts per volt or $-83 \mathrm{~dB}$; noise from the power supply or noise picked up by the supply lines was effectively eliminated. This would not take place using the single MOS impedance transformer originally considered for this work. The non-uniformity of transfer functions previously discussed could easily couple unwanted common mode noise into the system. The low output impedance effectively isolated the output line from noise.

When the data were first being taken, the skin was prepared by washing with methanol; however, as work proceeded, it was found that signal quality was not degraded by leaving the skin unprepared. This represents a significant improvement over paste electrodes, which require not only degreasing, but usually abrasion or removal of the outer layer of the skin (the stratum corneum). Application time and subject discomfort is reduced. 


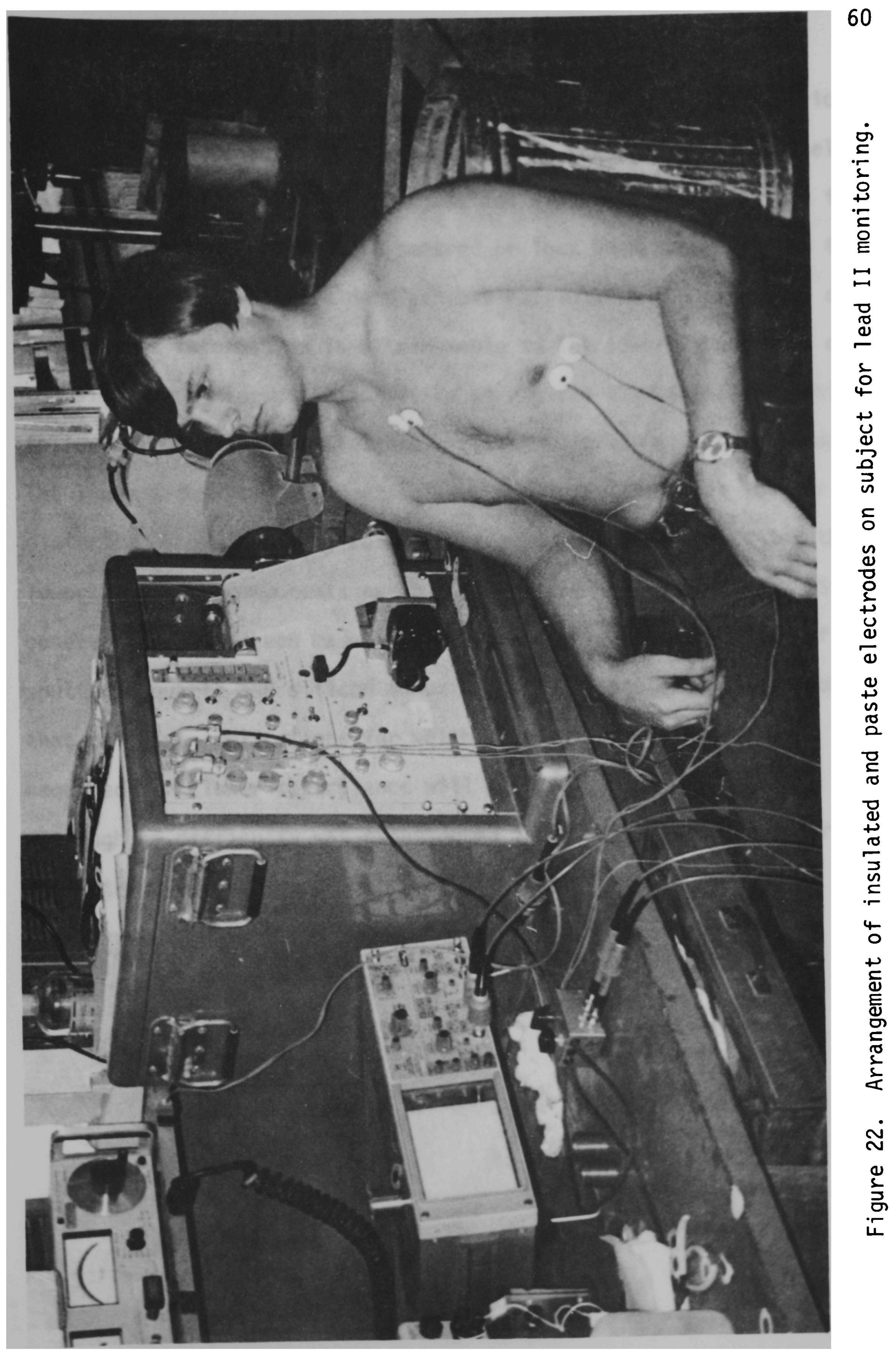


With film thicknesses comparable to those of other dielectric films, the electrocardiograms obtained with the silicon dioxide electrodes showed the peaks of the $P, R$, and $T$ waves quite well, but intermediate waveform details were smeared or lost when compared with the reference paste electrode data and other insulated ECG electrode data. The loss of information is attributable to the lower capacitance of the silicon dioxide capacitor discs at a given film thickness, which followed from the lower dielectric constant of the silicon dioxide. The lower frequency components of the ECG information are lost or distorted because of the reduced electrode bandwidth, that is, the lower frequency components are blocked by the low capacitance. Similar observations have been made using electrodes formed with films of sputtered quartz and silicon monoxide. ${ }^{(5)}$ It should be pointed out that in those applications for which clinical precision is not required, the lower capacitance will also reduce baseline drift, although no difficulty was experienced in this respect when other dielectrics were used. 


\section{CHAPTER VI}

\section{CONCLUSIONS}

It has been demonstrated that a variety of electrocardiographic electrodes can be obtained by the use of r.f. sputtering of dielectric targets onto a silicon substrate. Although electrodes have been made for only four dielectric films, the fabrication technique is general enough so that any dielectric may be used, providing that no skin toxicity exists. The electrodes were at least as insensitive to noise as paste electrodes, and possibly superior. Uniform transfer functions were obtained for the electrodes with the same dielectrics and similar thicknesses. The electrodes require no skin preparation before their use, and provide electrocardiograms which are comparable in quality to those obtained using standard paste electrodes. 


\section{LIST OF REFERENCES}

1. L.A. Geddes and L.E. Baker, Principles of Applied Biomedical Instrumentation. New York: John Wiley \& Sons, Inc., (1968).

2. C.D. Wheelwright, "Physiological Sensors for Use in Project Mercury," NASA Manned Spacecraft Center Technical Note D-1082 (1969).

3. L.F...Montes, J.L. Day, and L. Kennedy, "The Response of Human Skin to Long-Term Space Flight Electrodes," J. Invest. Dermotol., vol. 49, pp. 100-102 (1967).

4. P.C. Richardson, "The Insulated Electrode: A Pasteless Electrocardiographic Technique," 20th Annual Conference on Engineering in Medicine and Biology, Boston (1967).

5. P.C. Richardson, F.K. Coombs, and R.M. Adams, "Some New Electrode Techniques for Long-Term Physiological Monitoring," Aerospace Medicine, vol. 39, p. 745 (7968).

6. P.C. Richardson and F.K. Coombs, "New Construction Techniques for Insulated Electrocardiographic Electrodes," Proc. A.C.E.M.B., vol. 10, p. 13A1 (1968).

7. A. Lopez, Jr. and P.C. Richardson, "Capacitive Electrocardiographic and Bioelectric Electrodes," IEEE Trans. on Bio-Medical Engineering vol. BME-16, p. 99 (1969).

8. R.N. Wolfson and M.R. Newman, "Miniature Silicon-Silicon Dioxide Insulated Electrodes Based on Semiconductor Technology," Proc. A.C.B.M.B., vol. 11, pp. 14-16, (1969).

9. H.G. Rylander, P.C. Richardson, H.L. Taylor, and F.B. Vogt, "Capacitive Electrocardiographic Electrodes," Technical Report 99 (AFOSR-70-2437TR), Joint Serv. Electron. Prog. (1970).

10. W.M. Kaufman, "Development of Improved Capacitive Electrodes for Electrocardiographic Monitoring," Final Technical Report (NIH-692239) Medical Devices Applications Program (1970).

11. F.K. Coombs, Brooks Air Force Base, Texas, Telephone and Personal Comunuications.

12. P.C. Richardson, Department of Electrical Engineering, University of Texas at Austin, Texas, Telephone and Personal Communications.

13. Report of the Subcommittee on Instrumentation Committee on Electrocardiography, American Heart Association," Recommendations for Standardization of Instruments in Electrocardiography and Vector Cardiography," IEEE Transactions on Bio-Medical Engineering, vol. BME-14, No. 1, pp. 60-68 (1967). 
14. N.I. Sax, Dangerous Properties of Industrial Materials, New York: Reinhold Publishing Corp., (1963). 